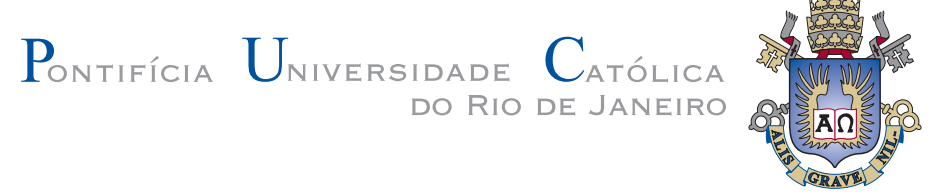

Marcelo de Mattos Nascimento

\title{
Utilizando reconstrução 3D densa para odometria visual baseada em técnicas de structure from motion
}

Dissertação apresentada como requisito parcial para obtenção do grau de Mestre pelo Programa de Pós-graduação em Informática do Departamento de Informática da PUC-Rio

Orientador: Prof. Alberto Barbosa Raposo 
Marcelo de Mattos Nascimento

\author{
Utilizando reconstrução 3D densa para \\ odometria visual baseada em técnicas de \\ structure from motion
}

Dissertação apresentada como requisito parcial para obtenção do grau de Mestre pelo Programa de Pós-graduação em Informática do Departamento de Informática do Centro Técnico Científico da PUC-Rio.Aprovada pela Comissão Examinadora abaixo assinada.

\author{
Prof. Alberto Barbosa Raposo \\ Orientador \\ Departamento de Informática — PUC-Rio \\ Prof. Marcelo Gattass \\ Departamento de Informática — PUC-Rio
}

Manuel Eduardo Loaiza Fernandez

Departamento de Informática - PUC-Rio

Prof. José Eugênio Leal

Coordenador Setorial do Centro Técnico Científico - PUC-Rio

Rio de Janeiro, 17 de Setembro de 2015 
Todos os direitos reservados. É proibida a reprodução total ou parcial do trabalho sem autorização da universidade, do autor e do orientador.

\section{Marcelo de Mattos Nascimento}

Graduou-se em Engenharia de Computação na Pontifícia Universidade Católica do Rio de Janeiro em 2010.

Ficha Catalográfica

Nascimento, Marcelo de Mattos

Utilizando reconstrução 3D densa para odometria visual baseada em técnicas de structure from motion / Marcelo de Mattos Nascimento; orientador: Prof. Alberto Barbosa Raposo. - Rio de Janeiro : PUC-Rio, Departamento de Informática, 2015.

v., 59 f: il. ; $29,7 \mathrm{~cm}$

1. Dissertação (mestrado) - Pontifícia Universidade Católica do Rio de Janeiro, Departamento de Informática.

Inclui referências bibliográficas.

1. Informática - Dissertação. 2. Odometria visual. 3. Reconstrução 3D densa. 4. SFM. 5. Kinect Fusion. 6. Visão Computacional. 7. Realidade Aumentada. I. Raposo, Alberto Barbosa. II. Pontifícia Universidade Católica do Rio de Janeiro. Departamento de Informática. III. Título. 


\section{Agradecimentos}

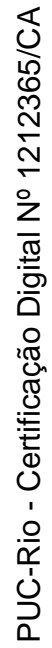

Ao meu orientador e minha família. Sem a ajuda de Tia Helida e Felipe Martins esse trabalho não seria possível, Meu muito obrigado aos dois. 


\section{Resumo}

Nascimento, Marcelo de Mattos; Raposo, Alberto Barbosa. Utilizando reconstrução $3 \mathrm{D}$ densa para odometria visual baseada em técnicas de structure from motion. Rio de Janeiro, 2015. 59p. Dissertação de Mestrado — Departamento de Informática, Pontifícia Universidade Católica do Rio de Janeiro.

Alvo de intenso estudo da visão computacional, a reconstrução densa 3D teve um importante marco com os primeiros sistemas em tempo real a alcançarem precisão milimétrica com uso de câmeras RGBD e GPUs. Entretanto estes métodos não são aplicáveis a dispositivos de menor poder computacional. Tendo a limitação de recursos computacionais como requisito, o objetivo deste trabalho é apresentar um método de odometria visual utilizando câmeras comuns e sem a necessidade de GPU, baseado em técnicas de Structure from Motion (SFM) com features esparsos, utilizando as informações de uma reconstrução densa. A Odometria visual é o processo de estimar a orientação e posição de um agente (um robô, por exemplo), a partir das imagens. Esta dissertação fornece uma comparação entre a precisão da odometria calculada pelo método proposto e pela reconstrução densa utilizando o Kinect Fusion. O resultado desta pesquisa é diretamente aplicável na área de realidade aumentada, tanto pelas informações da odometria que podem ser usadas para definir a posição de uma câmera, como pela reconstrução densa, que pode tratar aspectos como oclusão dos objetos virtuais com reais.

\section{Palavras-chave}

Odometria visual; Reconstrução 3D densa; SFM; Kinect Fusion; Visão Computacional; Realidade Aumentada; 


\section{Abstract}

Nascimento, Marcelo de Mattos; Raposo, Alberto Barbosa (Advisor). Using dense $3 \mathrm{D}$ reconstruction for visual odometry based on structure from motion techniques. Rio de Janeiro, 2015. 59p. MSc Thesis — Departamento de Informática, Pontifícia Universidade Católica do Rio de Janeiro.

Aim of intense research in the field computational vision, dense 3D reconstruction achieves an important landmark with first methods running in real time with millimetric precision, using RGBD cameras and GPUs. However these methods are not suitable for low computational resources. Having low computational resources as requirement, the goal of this work is to show a method of visual odometry using regular cameras, without using a GPU. The proposed method is based on technics of sparse Structure From Motion (SFM), using data provided by dense 3D reconstruction. Visual odometry is the process of estimating the position and orientation of an agent (a robot, for instance), based on images. This dissertation compares the proposed method with the odometry calculated by Kinect Fusion. Results of this research are applicable in augmented reality. Odometry provided by this work can be used to model a camera and the data from dense 3D reconstruction, can be used to handle occlusion between virtual and real objects.

\section{Keywords}

Visual Odometry; Dense 3D Reconstruction; SFM; Kinect Fusion; Computer Vision; Augment Reality; 


\section{Sumário}

1 Introdução $\quad 9$

$\begin{array}{ll}1.1 \text { Motivação } & 10\end{array}$

$\begin{array}{lll}1.2 & \text { Objetivo } & 10\end{array}$

$\begin{array}{lll}1.3 & \text { Organização do Trabalho } & 10\end{array}$

2 Trabalhos Relacionados $\quad 12$

2.1 Odometria Visual Esparsa 12

$\begin{array}{lll}2.2 & \text { Odometria Visual Densa } & 13\end{array}$

3 Base Teórica $\quad 15$

3.1 Modelo de Câmera Pinhole $\quad 15$

3.2 Modelo Geométrico Para Formação de Imagem 16

3.3 Mapa Exponencial 18

3.4 Métodos de Mínimos Quadrados 21

3.5 FREAK (Fast Retinal Keypoint) 23

3.6 SURF Detector(Fast Hessian Detector) 25

$\begin{array}{lll}3.7 & \text { Kinect Fusion } & 28\end{array}$

4 Método Proposto 32

4.1 Mapa off-line 32

4.2 Odometria em Tempo Real 34

5 Resultados $\quad 41$

5.1 Experimento 41

5.2 Cena $1+42$

$\begin{array}{lll}5.3 & \text { Cena } 2 & 48\end{array}$

6 Conclusão e Trabalhos Futuros $\quad 54$ 


\section{Lista de figuras}

3.1 Corte lateral de uma câmera escura $\quad 15$

3.2 Transformando coordenadas do plano retinal para pixels 17

3.3 Patch FREAK com distribuição de pontos similar a distribuição de células na retina, os círculos representam diferentes tamanhos de kernel para suavização gaussiana 24

3.4 Todos os 512 pares e grupos para comparação em cascata 24

3.5 conjuntos de pares de pontos usados para o cálculo da orientação 25

3.6 Vizinhos para non-maximum suppression, 3 oitavas com suas escalas 27

3.7 Aproximações $L_{y y}$ e $L_{x y}$ conhecidas como $D_{y y}$ e $D_{x y}$, usando conjuntos de filtros de caixa com $s=1.2$

3.8 Representação do volume TSDF. Cada elemento do grid representa um voxel; a superfície está implicitamente representada pelo zerocrossing onde há a troca do sinal do valor TSDF. Os valores TSDF aumentam em módulo com a distância da superfície; valores negativos estão atrás e positivos na frente.

4.1 Fluxo da construção do mapa off-line 33

4.2 Fluxo do cálculo da odometria 34

4.3 Procedimento de filtragem das correspondências mais fortes 36

4.4 Ângulo e distância entre duas poses 40

5.1 Cena $1 \quad 42$

5.2 Outliers presentes no matching 43

5.3 Eixo $Y$, mediana do erro de reprojeção em roxo. Área em ciano, valor da mediana limitada por MAD. Eixo X, imagens 44

5.4 Distância em centímetros em relação ao Fusion 45

5.5 Ângulos de Euler sobrepostos da pose calculada em relação ao Kinect Fusion. Convenção: $\operatorname{roll}(\mathrm{X})$-pitch(Y)-yaw(Z) 45

5.6 Visualização 3D da odometria calculada (cena 1) 47

5.7 Cena 2

5.8 Distância em centímetros em relação ao Fusion (cena 2) 50

5.9 Ângulos de Euler sobrepostos da pose calculada em relação ao Kinect Fusion. Convenção: $\operatorname{roll}(\mathrm{X})$-pitch(Y)-yaw(Z) (cena 2) 50

5.10 Eixo $Y$, mediana do erro de reprojeção em roxo. Área em ciano, valor da mediana limitada por MAD. Eixo X, imagens 51

5.11 outliers no matching resulta na piora da qualidade do cálculo da pose (cena 2)

5.12 Visualização 3D da odometria calculada (cena 2) 53 


\section{Introdução}

Aplicações que utilizam câmeras como um dos sensores principais estão cada vez mais presentes, como realidade aumentada em transmissões ao vivo, propagandas e jogos eletrônicos. Outra área em que as câmeras são usadas como sensores é a robótica, usada como um dos sensores para permitir o controle de drones[1] e carros autônomos[2]. O uso comum e crucial nos casos acima é estimar a posição e orientação, por exemplo: modelar uma câmera para aumentar uma cena e na robótica, para estimar a posição e orientação de um agente. Este processo de estimar a orientação e posição com uma câmera é conhecido como odometria visual. O primeiro trabalho sobre este assunto, desenvolvido por Moravec[3], data do início da década de 80 e tinha como objetivo o controle de uma sonda robótica. Blocos do seu pipeline continuam relevantes, como o uso de pontos de interesse. Nesse trabalho é apresentado um dos primeiros detectores de cantos.

A odometria visual é um subconjunto de um problema mais geral conhecido como structure from motion (SFM)[4], que consiste em recuperar pose de câmeras junto com a estrutura 3D a partir de um conjunto de imagens. O problema é mais geral, porque não se supõe que o conjunto de imagens tenha uma ordem específica. A reconstrução frequentemente é refinada com bundle adjustment[4] offline. Exemplo de aplicações que usam SFM e são refinadas off-line são o Google Maps e o Microsoft Photo Synth[5]. A odometria visual, por outro lado, se concentra em calcular a posição sequencialmente a medida que processa novos quadros. Quando além da odometria visual é criado um mapa do ambiente, surgem os métodos visual simoultaneous localization and mapping(SLAM) como em Davison et al.[6], Klein e Murray[7], Grisetti et al.[8]. Estes métodos apresentam maior precisão devido às restrições que podem ser impostas à trajetória, quando uma área é revisitada ou simplesmente pela não repetição do cálculo de informações já conhecidas com acúmulo de erro.

Ao contrário dos métodos visual SLAM que buscam o tempo real, os métodos de reconstrução densa que recuperam a geometria de uma cena, também baseados em odometria visual, até pouco tempo concentravam-se em métodos offline como Furukawa e Ponce[9]. Recentemente, métodos de reconstrução densa como Kinect Fusion[10], alcançaram taxas de tempo real para reconstruir cenas com volume de um cômodo, com o uso de GPUs. O 
Kinect Fusion usa um modelo global denso e uma câmera RGBD ${ }^{1}$, alcançando uma grande precisão na reconstrução. As aplicações são diversas, pois tanto a odometria em tempo real está disponível, como a geometria densa da cena. Por exemplo, essas informações podem servir para um agente desviar de obstáculos durante sua navegação. A geometria também pode ser usada em aplicações de realidade aumentada, por exemplo: pode ser utilizada para tratar oclusão entre real e virtual e simular com realismo a interação entre objetos reais e virtuais via simulação física.

\section{1 \\ Motivação}

A motivação deste trabalho é unir os dados de uma reconstrução densa 3D previamente feita pelo Kinect Fusion, com a odometria calculada por um pipeline clássico de SFM com features esparsos, sem uso de uma GPU nem de uma câmera RGBD. Deste modo, as informações como a geometria densa de uma cena estão disponíveis e a odometria pode ser calculada em dispositivos de menor poder computacional.

\section{2}

\section{Objetivo}

O objetivo deste trabalho é implementar um método para o cálculo da odometria visual usando pipeline para features esparsos com ajuste local e informações de reconstrução densa, no caso, a posição 3D de pontos da reconstrução junto com as informações 2D dos features. Para avaliar a precisão e o desempenho do sistema aqui proposto, seus resultados serão comparados com os obtidos com o Kinect Fusion.

\section{3}

\section{Organização do Trabalho}

O texto desta dissertação está organizado da seguinte forma. O capítulo 2 fornece um resumo dos trabalhos relacionados com a reconstrução densa e a odometria visual não densa. O capítulo seguinte apresenta os conceitos teóricos usados, como câmera pinhole, movimento de corpo rígido, um método para o cálculo de mínimos quadrados não linear e uma descrição detalhada de trabalhos utilizados que são: o Kinect Fusion, o detector SURF e o descritor FREAK. O quarto capítulo descreve a arquitetura do método proposto, detalhando a construção de um mapa com informações da reconstrução densa

\footnotetext{
${ }^{1}$ Câmeras RGBD capturam simultaneamente a cor RGB e a profundidade de um pixel
} 
Utilizando reconstrução 3D densa para odometria visual baseada em técnicas de structure from motion

e o pipeline não denso para o cálculo da odometria visual. O quinto capítulo fornece os resultados da comparação do método proposto com o Kinect Fusion em duas cenas. Finalmente, o sexto capítulo apresenta uma conclusão sobre este trabalho e propostas de trabalhos futuros. 


\section{2}

\section{Trabalhos Relacionados}

A odometria visual é um tema extensamente estudado[11]. Possui uma miríade de técnicas e uso de diferentes tipos de câmeras. As câmeras podem ser RGB, RGBD, variando-se o tipo de lente, sua calibração prévia ou autocalibração e a disposição mono, estéreo ou mais câmeras. Este texto se concentrará em técnicas em tempo real que utilizam uma única câmera comum calibrada ou uma única câmera RGBD.

Apesar da grande variedade de técnicas, as mesmas podem ser classificadas em dois tipos: as que se baseiam em informações esparsas e as que se baseiam em densas. As técnicas esparsas utilizam apenas uma parte da imagem disponível, como pontos ou uma área, que possam ser identificados em uma outra imagem. Por outro lado as técnicas densas utilizam toda a imagem. Até recentemente, a abordagem densa se restringia a métodos offline. Com a melhora dos recursos computacionais como o uso de GPUs, essas técnicas puderam ser implementadas em tempo real.

\section{1}

\section{Odometria Visual Esparsa}

Diversas técnicas de odometria visual esparsa foram implementadas com sucesso para o uso em aplicações de realidade aumentada e também para o controle de agentes na robótica. O pipeline típico destes métodos, como descrito por Nistér et al.[12], consiste em primeiramente extrair pontos de interesse com uso de detectores como Harris[13] e FAST[14] e depois estabelecer a correspondência entre os pontos de interesse calculados do quadro atual com o anterior. Essa correspondência é feita comparando uma área ao redor dos pontos, usando a métrica de distância do erro fotométrico ou com uso de descritores como SURF[15] e FREAK[16]. O uso de descritores torna a correspondência mais robusta, pois os mesmos são feitos para serem resistentes, por exemplo, à escala, rotação e mudanças na iluminação. Esses benefícios geralmente vêm com maior uso de recursos computacionais. Finalmente, a transformação de corpo rígido entre quadros consecutivos é estimada com métodos 2D-2D decompondo a matriz essencial, ou 2D-3D com triangulação[17] entre pares de pontos anteriores com a pose conhecida e a correspondência 2D-3D entre pontos 3D e suas projeções. Recuperar a pose utilizando estas correspondências é conhecida como space resection, como 
descrito em Haralick et al.[18]. A vantagem do cálculo 2D-3D sobre 2D-2D é a quantidade de pontos necessários. Na decomposição da matriz essencial são no mínimo 5 pontos e para o space resection no mínimo 3 pontos[18]. Uma desvantagem dos métodos 2D-3D é que precisam ser inicializados com métodos 2D-2D afim de triangular o primeiro conjunto de pontos 3D. O estágio de correspondência de pontos de interesse não é livre de erros e a quantidade de pontos é importante para a de filtragem de outliers utilizando métodos como RANSAC[19]. No RANSAC a validade dos inliers é feita usando conjunto mínimo de valores para testar o modelo, ao contrário do método de mínimos quadrados que utiliza todos os dados disponíveis. Após o cálculo da pose, a precisão pode ser melhorada com bundle adjustment entre os $N$ últimos quadros.

Métodos de optimização global com uso de mapa são utilizados para aprimorar a odometria reduzindo o acúmulo de erro. Os métodos SLAM concentram-se em três diferentes categorias:

- o uso de bundle adjustment global e um modelo de keyframes como no PTAM.

- Os filtros probabilísticos como em Davison et al.[6].

- As optimizações de grafo de poses como em Grisetti et al.[8].

Quando a odometria é feita apenas com a informação de uma câmera calibrada não é possível obter a escala original, entretanto é possível atualizar para uma reconstrução métrica, conhecendo alguma medida do ambiente. Esses dados podem ser obtidos com sensores IMU ${ }^{1}$ como são comumente utilizados na robótica. Quando há, além da odometria visual, a odometria de diversos sensores, o método Extended Kalman Filter pode ser usado para fundir os dados, como em Weiss et al.[20] .

\section{2}

\section{Odometria Visual Densa}

As técnicas de odometria densa, ao contrário da esparsa, utilizam informações de toda a imagem. Há basicamente duas abordagens principais: as baseadas no erro fotométrico e as baseadas no iterative closest point (ICP). As abordagens baseadas no erro fotométrico calculam o alinhamento entre duas imagens, usando uma transformação de corpo rígido que melhor alinhe a projeção dos pontos 3D do quadro anterior no quadro seguinte, minimizando o erro fotométrico da projeção $2 \mathrm{D}$ entre ambos os pixels correspondentes. Essa

1 Inertial measurement unit(IMU) são sensores como giroscópios, acelerômetros e magnetômetros que fornecem o valor instantâneo para medidas físicas 
abordagem é similar ao fluxo ótico, mas entre pontos 3D e pixels da imagem. Como é necessária a coordenada 3D, este método é geralmente feito com uso de uma câmera RGBD. Deste modo um pixel na imagem 2D, conhecendo-se sua profundidade, pode ser retro-projetado para sua coordenada 3D em relação a câmera. Utilizando apenas uma câmera, o DTAM[21] consegue extrair a profundidade para um quadro, através da análise de um conjunto de imagens preenchendo uma distância $d$, construindo um volume de custo discreto para atribuir um valor de profundidade a um determinado pixel. Deste modo é possível construir um conjunto de keyframes com a profundidade conhecida e criar novos keyframes projetando o mapa em uma pose específica. Com a posse da profundidade gerada pelo modelo de keyframes, o alinhamento pelo erro fotométrico pode ser feito. Embora o método descrito em DTAM funcione com uma câmera comum, o mesmo necessita de uma GPU para funcionar em tempo real.

O segundo tipo de abordagem para odometria visual densa são os métodos baseados no ICP. Estes métodos buscam alinhar com uma transformação de corpo rígido, um conjunto de pontos 3D a outro conjunto de pontos 3D, minimizando a distância entre pontos correspondentes. Há diversas variações do ICP. Uma muito utilizada é plane to point [22], em que, além da coordenada do ponto utiliza-se a normal dos mesmos na métrica para o cálculo do alinhamento. Um gargalo do método ICP é o cálculo dos pontos correspondentes. A correspondência pode ser estabelecida com uma busca de vizinho mais próximo usando, por exemplo, uma estrutura hierárquica como uma octree. Quando o dado está disponível em mapa de profundidade vindo de uma projeção como em uma câmera RGBD, a técnica conhecida como projective data association [23] pode ser utilizada com desempenho superior a busca de vizinhos mais próximos. O alinhamento com ICP e projective data association são usadas no Kinect Fusion e serão detalhadas no Capítulo 3.

Há ainda métodos híbridos com a função de custo utilizando tanto a métrica do erro fotométrico, quanto do alinhamento via ICP, como descrito em Tykkala et al.[24]. 


\section{3}

\section{Base Teórica}

Neste capítulo estão os conceitos matemáticos usados nesta dissertação como o modelo de câmera utilizado, parametrização de movimento de corpo rígido e método de mínimo quadrados. Também são discutidos com mais detalhes trabalhos relacionados utilizados que são: Kinect Fusion, detector de pontos de interesse SURF e descritor FREAK.

\section{1}

\section{Modelo de Câmera Pinhole}

O modelo de câmera adotado descreve a projeção de uma coordenada 3D passando pelo centro de projeção de uma câmera escura ideal, onde a abertura é descrita como um ponto e nenhuma lente é usada para focar a luz. Por não modelar o efeito de lentes ou abertura, nenhuma distorção ou desfoque é descrito. Apesar das limitações do modelo utilizado, o mesmo aproxima uma câmera moderna com mundo em foco e baixa distorção.

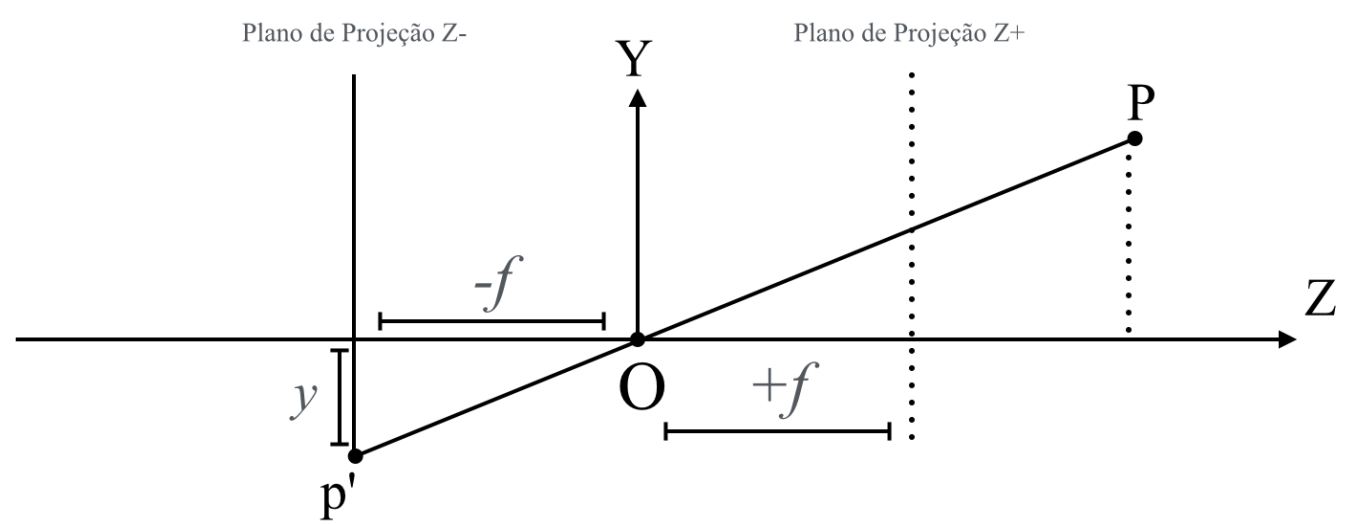

Figura 3.1: Corte lateral de uma câmera escura

\subsection{1}

\section{Imagem por uma câmera escura}

Pelo modelo de câmera escura, todos os raios são forçados a passar pelo centro ótico $O$, consequentemente, os únicos pontos que contribuem com irradiança no ponto da imagem $p^{\prime}$, com coordenada 2D $x=[x, y]^{T}$, são os 
Utilizando reconstrução 3D densa para odometria visual baseada em técnicas de structure from motion

que estão em linha com o centro $O . P$ é um ponto com coordenadas 3D $X=[X, Y, Z]^{T}$ relativas aos eixos de referência com origem no centro óptico, com eixo- $z$ perpendicular ao plano plano de projeção e $f$ a distância até o plano de projeção (figura 3.1) . Portanto por semelhança de triângulos tem-se a chamada equação da projeção perspectiva.

$$
x=-f \frac{X}{Z} \quad, \quad y=-f \frac{Y}{Z}
$$

\section{2}

\section{Modelo Geométrico Para Formação de Imagem}

A simplificação do modelo pinhole reduz o processo de formação de imagem ao traçado de raios de pontos de objetos em pixels. Para modelar este processo deve ser levado em conta as seguintes características:

1. Transformação entre o sistema de coordenadas da câmera e mundo.

2. Projeção das coordenadas 3-D em coordenadas 2-D de imagens.

3. Transformação da coordenada de imagem em outro sistema 2-D de coordenadas. representado por pixels.

\subsection{1}

\section{Câmera perspectiva ideal}

Considerando um ponto $P$ com coordenadas relativas ao mundo $\mathbf{X}_{\mathbf{0}}=$ $\left[X_{0}, Y_{0}, Z_{0}\right]^{T}$, podemos rescrever o mesmo ponto nas coordenadas relativas a origem da câmera por uma transformação de corpo rígido dada por $g=(R, T)$ de $\mathbf{X}_{\mathbf{0}}$ :

$$
\mathbf{X}=R \mathbf{X}_{\mathbf{0}}+T \quad \in \mathbb{R}^{3}
$$

Adotando a câmera pinhole com plano de projeção em Z+ (ver figura 3.1), pode-se re-escrever a equação da geometria perspectiva (eq. 3.1.1) como

$$
\mathbf{x}=\left(\begin{array}{l}
x \\
y
\end{array}\right)=\frac{f}{Z}\left(\begin{array}{l}
X \\
Y
\end{array}\right)
$$

e usando coordenadas homogêneas:

$$
Z\left[\begin{array}{l}
x \\
y \\
1
\end{array}\right]=\left[\begin{array}{llll}
f & 0 & 0 & 0 \\
0 & f & 0 & 0 \\
0 & 0 & 1 & 0
\end{array}\right] \mathbf{X} \quad, \quad \mathbf{X}=\left[\begin{array}{c}
X \\
Y \\
Z \\
1
\end{array}\right]
$$


Utilizando reconstrução 3D densa para odometria visual baseada em técnicas de structure from motion

acrescentando a transformação de corpo rígido:

$$
Z\left[\begin{array}{l}
x \\
y \\
1
\end{array}\right]=\left[\begin{array}{lll}
f & 0 & 0 \\
0 & f & 0 \\
0 & 0 & 1
\end{array}\right]\left[\begin{array}{llll}
1 & 0 & 0 & 0 \\
0 & 1 & 0 & 0 \\
0 & 0 & 1 & 0
\end{array}\right]\left[\begin{array}{cc}
R & T \\
0 & 1
\end{array}\right] \mathbf{X}_{\mathbf{0}}
$$

e definindo duas matrizes como

$$
K_{f}=\left[\begin{array}{lll}
f & 0 & 0 \\
0 & f & 0 \\
0 & 0 & 1
\end{array}\right] \quad, \quad \pi_{0}=\left[\begin{array}{llll}
1 & 0 & 0 & 0 \\
0 & 1 & 0 & 0 \\
0 & 0 & 1 & 0
\end{array}\right]
$$

pode-se formar a seguinte equação matricial

$$
\lambda \mathbf{x}=K_{f} \pi_{0} \mathbf{X}=K_{f} \pi_{0} g \mathbf{X}_{\mathbf{0}}
$$

\subsection{2}

\section{Parâmetros Intrínsecos}

A câmera do modelo ideal tem as coordenadas de imagem centradas no centro ótico de projeção. Entretanto, na prática as imagens estão em pixels $(i, j)$ com tamanho dos pixels diferentes dos pontos projetados no plano retinal e com a origem das coordenadas de imagem em outro ponto. Portanto é necessário modificar a equação 3.2.1 para refletir estas características.

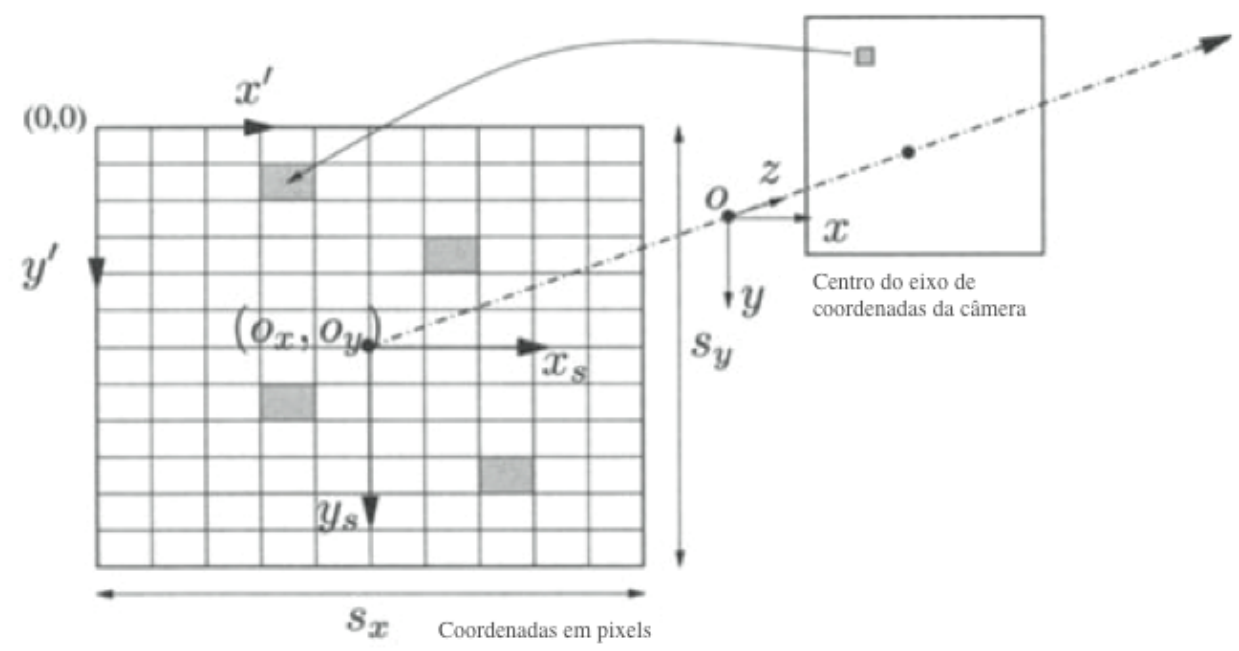

Figura 3.2: Transformando coordenadas do plano retinal para pixels

Primeiramente para tratar o tamanho diferente entre pontos $(x, y)$ no plano retinal e pixels $(i, j)$ é utilizada uma transformação de escala dada por:

$$
\left[\begin{array}{l}
x s \\
y s
\end{array}\right]=\left[\begin{array}{cc}
s x & 0 \\
0 & s y
\end{array}\right]\left[\begin{array}{l}
x \\
y
\end{array}\right]
$$


onde $s x$ é o tamanho do pixel na direção $x$ e sy o tamanho na direção $y$. Como a origem dos pixels $(i, j)$ adotada neste trabalho e na literatura de visão computacional está no canto superior esquerdo (figura 3.2), é necessário adicionar uma translação na equação acima:

$$
\mathbf{x}^{\prime}=\left[\begin{array}{c}
x^{\prime} \\
y^{\prime} \\
1
\end{array}\right]=\left[\begin{array}{ccc}
s_{x} & 0 & o_{x} \\
0 & s_{y} & o_{y} \\
0 & 0 & 1
\end{array}\right]\left[\begin{array}{l}
x \\
y \\
1
\end{array}\right] \quad, \quad K_{s}=\left[\begin{array}{ccc}
s_{x} & 0 & o_{x} \\
0 & s_{y} & o_{y} \\
0 & 0 & 1
\end{array}\right]
$$

onde $x^{\prime}$ e $y^{\prime}$ são as coordenadas em pixels e $\left(o_{x}, o_{y}\right)$ é a coordenada da origem dos pixels em relação a origem do plano retinal. A matriz que transforma os pontos. $\lceil x, y, 1\rceil^{T}$ para $\left\lceil x^{\prime}, y^{\prime}, 1\right\rceil^{T}$ é conhecida como $K_{s}$. Deste modo a equação 3.2.1 é modificada para:

$$
\lambda \mathbf{x}^{\prime}=K_{s} K_{f} \pi_{0} g \mathbf{X}_{\mathbf{o}}
$$

A concatenação das transformações $K_{s}$ e $K_{f}$ é conhecida como $K$ e contém todos os parâmetros intrínsecos de uma câmera particular. A matriz K também é conhecida como matriz de calibração e pode ser obtida por um método de calibração como OpenCV[25].

Matriz $K$ :

$$
K=\left[\begin{array}{ccc}
f s_{x} & 0 & o_{x} \\
0 & f s_{y} & o_{y} \\
0 & 0 & 1
\end{array}\right]
$$

substituindo a matriz $K$ na equação tem-se

$$
\lambda x^{\prime}=K \pi_{0} g X_{o}
$$

Normalmente é utilizado apenas uma transformação projetiva $\pi$ dada por

$$
\pi=K \pi_{0} g \quad \pi \in \mathbb{R}^{3 x 4}
$$

e finalmente

$$
\lambda x^{\prime}=\pi X_{o}
$$

\section{3}

\section{Mapa Exponencial}

Grande parte do trabalho proposto envolve resolver problemas de optimização com funções de custo na qual parte da parametrização utiliza transformações de corpo rígido. Portanto o modo de descrever essas transformações é crucial para este trabalho e deve levar em conta a facilidade 
Utilizando reconstrução 3D densa para odometria visual baseada em técnicas de structure from motion

de diferenciação e que a parametrização não envolva funções que limitem o sub-espaço utilizado, tal qual uma matriz de rotação em que

$$
R \in R^{3 x 3} \quad \mid \quad R R^{T}=I \quad \operatorname{det}(R)=1
$$

Este sub-espaço, mais a multiplicação de matrizes pertencentes ao mesmo é chamado de grupo das rotações $\mathrm{SO}(3)$

\subsection{1}

\section{Mapa Exponencial para Rotações}

Dada uma trajetória $R(t): \mathbb{R} \rightarrow S O(3)$ que descreve um movimento contínuo de rotação, a trajetória deve satisfazer a seguinte restrição:

$$
R(t) R^{T}(t)=I
$$

Derivando o produto acima como em[26], chega-se a equação:

$$
\dot{R}(t) R^{T}(t)+R(t) \dot{R}^{T}(t)=0
$$

Manipulando a equação chega-se à: $\dot{R}(t) R^{T}(t)=-\dot{R}(t) R^{T}(t)^{T}$, lembrando que $(A B)^{T}=B^{T} A^{T}$ e que matrizes da forma $A=-A^{T}$ são conhecidas como antissimétricas e dão origem ao conjunto $s o(3)$.

$$
s o(3)=\left\{\omega \in R^{3} \quad \hat{\omega}=\left[\begin{array}{ccc}
0 & \omega_{3} & \omega_{2} \\
-\omega_{3} & 0 & -\omega_{1} \\
-\omega_{2} & \omega_{1} & 0
\end{array}\right]\right\}
$$

Portanto tem-se:

$$
\dot{R}(t) R^{T}(t)=\hat{\omega}(t) \quad \omega \in R^{3}
$$

Multiplicando a equação acima pela direita por $R(t)$, obtém-se:

$$
\dot{R}(t)=\hat{\omega} R(t)
$$

que tem forma de uma equação matricial diferencial ordinária de primeira ordem

$$
\dot{x}(t)=A x(t)
$$

com solução para condição de contorno $R(0)=I$ dado por

$$
R(t)=e^{\hat{\omega} t}
$$


Utilizando reconstrução 3D densa para odometria visual baseada em técnicas de structure from motion

e com a expansão da série de Taylor

$$
e^{\hat{\omega} t}=I+\hat{\omega} t+\frac{(\hat{\omega} t)^{2}}{2 !}+\cdots+\frac{(\hat{\omega} t)^{n}}{n !}+\cdots
$$

Fazendo $t=\|\omega\|$ e normalizando $\omega$ chega-se a seguinte identidade com a potencia de $\hat{\omega}$ :

$$
\hat{\omega}^{2}=\omega \omega^{T}-I \quad \hat{\omega}^{3}=-\hat{\omega} \quad \hat{\omega}^{4}=-\hat{\omega}^{2} \quad \hat{\omega}^{5}=\hat{\omega} \quad \ldots
$$

Simplificando a série do mapa exponencial para:

$$
e^{\hat{\omega} t}=I+\left(t-\frac{t^{3}}{3 !}+\frac{t^{5}}{5 !}+\cdots\right) \hat{\omega}+\left(\frac{t^{2}}{2 !}-\frac{t^{4}}{4 !}+\frac{t^{6}}{6 !}-\cdots\right) \hat{\omega}^{2}
$$

onde a primeira série entre parênteses é de $\sin (t)$ e a segunda $(1-\cos (t))$. Deste modo chega-se a fórmula fechada do mapa exponencial, conhecida como Rodrigues[4]:

$$
e^{\hat{\omega} t}=I+\operatorname{sen}(t) \hat{\omega}+(1-\cos (t)) \hat{\omega}^{2}, \quad \exp : \operatorname{so}(3) \rightarrow S O(3)
$$

O operador $\log (R)=\omega$ é definido como[4]:

$$
\|\omega\|=\operatorname{acos}\left(\frac{\operatorname{traço}(R)-1}{2}\right), \quad \frac{\omega}{\|\omega\|}=\frac{1}{2 \operatorname{sen}(\|\omega\|)}\left[\begin{array}{l}
r_{32}-r_{23} \\
r_{13}-r_{31} \\
r_{21}-r_{12}
\end{array}\right]
$$

\subsection{2}

\section{Mapa exponencial para Transformações de Corpo Rígido}

Nesta seção são apresentadas as fórmulas que permitem o mapa de uma transformação de corpo rígido $g(R, T)$ para coordenadas exponenciais e no sentido inverso com a definição dos operadores $\log (g)$ e $\exp (\xi)[4]$.

$\xi$ é conhecido como vetor tangente de $g(t)$ e $\hat{\xi}$ a matriz conhecida como twist dado por:

$$
\operatorname{se}(3)=\left\{\hat{\xi}=\left[\begin{array}{ll}
\hat{\omega} & v \\
0 & 0
\end{array}\right] \quad \hat{\omega} \in \quad s o(3), \quad v \in R^{3}\right\}
$$

e o mapa de exp:se $(3) \rightarrow S E(3)$ é dado por:

$$
e^{\hat{\xi}}=\left[\begin{array}{cc}
e^{\hat{\omega}} & \frac{\left(I-e^{\hat{\omega}}\right) \hat{\omega} v+\omega \omega^{T} v}{\|\omega\|} \\
0 & 1
\end{array}\right]
$$

O operador $\log (g)$ pode ser calculado usando o $\log (R)$ para parte da rotação 
Utilizando reconstrução 3D densa para odometria visual baseada em técnicas de structure from motion

seguido sistema abaixo para o calculo de $v$ :

$$
\frac{\left(I-e^{\hat{\omega}}\right) \hat{\omega} v+\omega \omega^{T} v}{\|\omega\|}=T
$$

\section{4}

\section{Métodos de Mínimos Quadrados}

A técnica de mínimos quadrados estima os melhores parâmetros de um modelo utilizando medidas reais, minimizando o quadrado do erro entre o valor observado e o previsto.

\subsection{1}

\section{Definição Matemática}

O método busca estimar o melhor valor para um modelo $f(x, \theta) \quad \mathbb{R}^{n} \rightarrow \mathbb{R}$ sendo $\theta$ os valores dos parâmetros e $y$ o conjunto dos valores observados. Minimizando com a seguinte equação:

$$
\operatorname{argmin} \sum_{i}^{n}\left(y_{i}-f\left(x_{i}, \theta\right)\right)^{2}
$$

a diferença $r_{i}\left(\theta, x_{i}\right)=y_{i}-f\left(x_{i}, \theta\right)$ é conhecida como residual. Os possíveis mínimos ou mínimo, caso $f$ seja linear, são obtidos quando a derivada parcial da soma dos residuais é zero.

$$
\sum_{i}^{n} 2 r_{i}\left(\theta, x_{i}\right) \frac{\partial r_{i}\left(\theta, x_{i}\right)}{\partial \theta}=0
$$

Um sistema linear pode ser representado pela seguinte forma:

$$
f=X \theta-Y \quad x_{i}=\left[\begin{array}{lll}
x_{1} & \ldots & x_{k}
\end{array}\right] \quad \theta=\left[\begin{array}{c}
\theta_{1} \\
\vdots \\
\theta_{k}
\end{array}\right] Y=\left[\begin{array}{c}
y_{1} \\
\vdots \\
y_{n}
\end{array}\right]
$$

usando a equação 3.4.1 com o sistema linear tem se:

$$
\sum_{i}^{n}\left(x_{i} \theta-y_{1}\right) x_{i}^{T}=0
$$

rescrevendo a equação acima na forma matricial chega-se na equação normal

$$
X^{T} X \theta=X^{T} Y
$$


Utilizando reconstrução 3D densa para odometria visual baseada em técnicas de structure from motion

O sistema linear resultante pode ser resolvido usando um método de solução para sistemas lineares como a decomposição QR.

\subsection{2}

\section{Mínimos Quadrados não Linear}

Caso $f(x, \theta)$ seja não linear, o problema deve ser linearizado usando um ponto próximo à solução, pois a solução da equação 3.4.1 pode não convergir, ou convergir para um mínimo não global e até mesmo para um ponto de máximo ou sela.

Sendo $\theta^{k}$ o ponto onde o residual $r$ será linearizado, usando a expansão da série de Taylor de primeira ordem:

$$
r_{i}(\theta) \approx r_{i}\left(\theta^{(k)}\right)+\nabla r_{i}\left(\theta^{(k)}\right)^{T}\left(\theta-\theta^{(k)}\right)
$$

o novo valor de $\theta^{k+1}$ é o mínimo da soma dos quadrados dos resíduos linearizados:

$$
\sum_{i}^{n}\left(r_{i}\left(\theta^{(k)}\right)+\nabla r_{i}\left(\theta^{(k)}\right)^{T}\left(\theta-\theta^{(k)}\right)\right)^{2}
$$

Rescrevendo com $\theta-\theta^{(k)}=\Delta$ e $\theta^{(k+1)}=\Delta+\theta^{(k)}$

$$
\sum_{i}^{n}\left(r_{i}\left(\theta^{(k)}\right)+\nabla r_{i}\left(\theta^{(k)}\right)^{T} \Delta\right)^{2}
$$

o sistema fica com a forma $f=X \theta+Y \operatorname{com} X=J(\theta), Y=r(\theta)$ e $\theta=\Delta$, sendo $J=\partial r / \partial \theta$. Deste modo a minimização pode ser resolvida pela equação normal (3.4.2) com a fórmula:

$$
J\left(\theta^{(k)}\right) J\left(\theta^{(k)}\right)^{T} \Delta=-J\left(\theta^{(k)}\right)^{T} r\left(\theta^{(k)}\right)
$$

O processo iterativo é repetido até que se ache a solução com a precisão necessária ou um número máximo de iterações tenha sido excedido.

\subsection{3}

\section{Mínimos Quadrados não Linear Ponderado}

A presença de dados fora do modelo afeta bastante a minimização pois a mesma é baseada no quadrado do erros do residuais. Geralmente esses dados são devidos a outliers que não são explicados pelo modelo. Uma forma de mitigar esses residuais é criar uma função robusta que os atenue, caso passem de determinado valor. Os residuais podem ser minimizados por uma nova 
função com a equação:

$$
\operatorname{argmin} \sum_{i} \rho\left(r_{i}^{2}\right)
$$

Fazendo a equação igual a zero como em 3.4.1, a equação normal fica com a forma:

$$
J\left(\theta^{(k)}\right)^{T} W J\left(\theta^{(k)}\right)=-J\left(\theta^{(k)}\right)^{T} W r\left(\theta^{(k)}\right)
$$

onde $W$ é uma matriz diagonal em que cada elemento da diagonal é dado por $W_{i i}=\omega\left(r_{i}\right) \quad \omega=\rho^{\prime}$. O cálculo da matriz $W$ deve ser feito a cada nova estimativa de $\theta^{(k)}$.

A função $\omega$ é conhecida na literatura de análise de regressão como M-Estimator, termo cunhado por Huber et al.[27].

\section{5}

\section{FREAK (Fast Retinal Keypoint)}

FREAK é um descritor binário usado para medir a similaridade entre keypoints(pontos de interesse), composto de 3 partes comuns aos descritores deste tipo[16]:

- um padrão para amostra de pares de pontos em um patch centrado em um keypoint.

- uma métrica para medir a orientação do descritores e rotacioná-los para compensar mudanças de orientação.

- cálculo do descritor comparando os pares do padrão com alguma heurística.

\subsection{1}

\section{Padrão de pares de Pontos}

O descritor FREAK possui um padrão da distribuição dos pares de pontos similar a distribuição de células da retina humana ( figura 3.3). O conjunto de 512 pares entre os pontos são previamente treinados; os detalhes desta técnica podem ser vistos em [16]. Os pares são escolhidos para permitir uma comparação em cascata (figura 3.4), somente se a distância de Hamming entre os primeiros $n$ bits for menor que um limiar, que os outros próximos bits serão avaliados. 


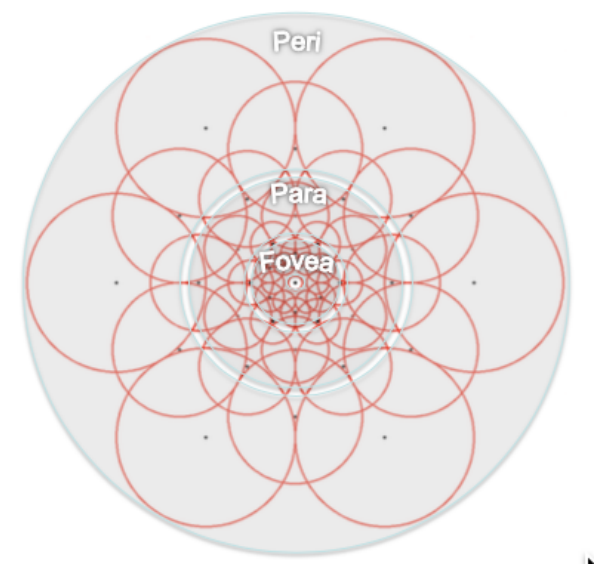

Figura 3.3: Patch FREAK com distribuição de pontos similar a distribuição de células na retina, os círculos representam diferentes tamanhos de kernel para suavização gaussiana

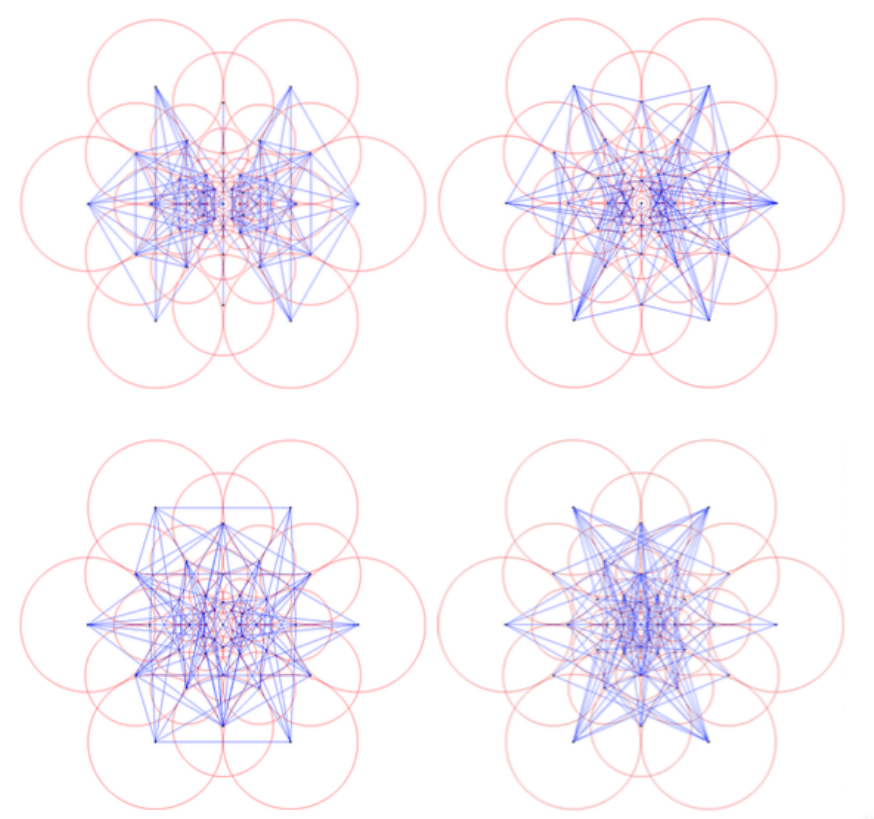

Figura 3.4: Todos os 512 pares e grupos para comparação em cascata

\subsection{2}

\section{Cálculo da Orientação}

O cálculo da orientação utiliza o gradiente entre um subconjunto dos pares da amostra definido por:

$$
\begin{gathered}
g\left(p_{i}, p_{j}\right)=\left(p_{j}-p_{i}\right) \cdot \frac{I\left(p_{j}, \sigma_{j}\right)-I\left(p_{i}, \sigma_{i}\right)}{\left\|p_{j}-p_{i}\right\|} \\
O=\frac{1}{M} \sum_{\left(p_{i}, p_{j}\right) \in G} g\left(p_{i}, p_{j}\right)
\end{gathered}
$$


sendo $G$ o conjunto de pares de pontos $\left(p_{i}, p_{j}\right)$ usados no cálculo do gradiente e a função $I$ é o ponto $p$ suavizado pelo kernel $\sigma$ de acordo com a posição do mesmo (figura3.3). O ângulo do descritor é dado pelo arco tangente das componentes $O_{x} / O_{y}$. Com o ângulo do descritor calculado, os pontos da amostra são rotacionados pelo mesmo.

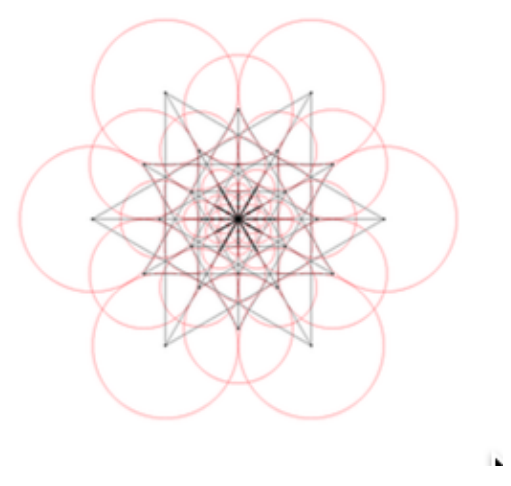

Figura 3.5: conjuntos de pares de pontos usados para o cálculo da orientação

\subsection{3}

\section{Cálculo do Descritor}

O cálculo do descritor é o resultado da comparação entre os pares do patch suavizados pelo seu respectivo kernel, dado por:

$$
b= \begin{cases}1 & I\left(p_{j}, \sigma_{j}\right)>I\left(p_{i}, \sigma_{i}\right) \\ 0 & \text { senão }\end{cases}
$$

A concatenação do resultado dessas comparações resulta no descritor. O descritor pode ser comparado usando a técnica de comparações em cascata ou comparando a distância de Hamming diretamente entre os dois descritores.

\section{6}

\section{SURF Detector(Fast Hessian Detector)}

O detector SURF é projetado para achar keypoints invariantes a operações de escala em uma imagem. Isto é geralmente feito analisando a resposta a uma função na imagem em diferentes escalas.

O detector SURF implementa este espaço sem reduzir a imagem subamostrando sucessivos kernels gaussianos. Os cálculos são todos feitos na imagem original aumentando-se o tamanho do kernel; esses cálculos são 
feitos de forma eficiente utilizando imagens integrais ${ }^{1}$ e aproximando o filtro gaussiano por filtros de caixa. O detector SURF utiliza a resposta ao Hessiano para achar os pontos de interresse e o mesmo é dado por:

$$
\mathcal{H}(x, \sigma)=\left[\begin{array}{ll}
L_{x x}(x, \sigma) & L_{x y}(x, \sigma) \\
L_{x y}(x, \sigma) & L_{y y}(x, \sigma)
\end{array}\right]
$$

onde

$$
L_{x x}(x, \sigma)=I(x) * \frac{\partial^{2}}{\partial x^{2}} g(\sigma)
$$

$L_{x x}$ é a convolução da imagem pela derivada de segunda ordem do kernel gaussiano. O detector SURF funciona analisando a resposta do determinante do Hessiano aproximado em uma vizinhança espacial constituída de 3x3x3 pontos, verificando se o ponto é o máximo emtre os vizinhos(non-maximum suppression). Caso seja, este ponto é marcado como um keypoint. Esta vizinhança constitui-se de pontos vizinhos na mesma escala e pontos nas escalas vizinhas (figura 3.6) . O detector SURF constrói uma escala fazendo um pirâmide de respostas ao Hessiano variando o valor de $\sigma$. Este espaço está subdividido em oitavas que consistem em dobrar o valor $\sigma$, e as oitavas estão subdivididas uniformemente (figura 3.6).

O cálculo das derivadas é feito aproximando a derivada do kernel gaussiano por filtros de caixa. A figura 3.7 mostra a configuração dos filtros de caixa com $\sigma \simeq 1.2$ com tamanho 9x9. Valores maiores de $\sigma$ correspondem ao aumento do tamanho do kernel com a seguinte formula, $s=1.2 \frac{K}{9}$ onde $K$ é o tamanho do kernel e $s \simeq \sigma$. O determinante aproximado é dado pela equação:

$$
\operatorname{Det}\left(H_{\text {aprox }}\right)=D_{x x} D_{y y}-\left(\omega D_{x y}\right)^{2}
$$

onde $D_{x x}$ são aproximações para $L_{x x}$. O valor de $\omega$ deve ser ajustado de acordo com o tamanho do kernel a fim de manter a conservação da energia do kernel gaussiano[15]; em implementações práticas esse valor é mantido constante com $\omega=0.9$.

Após achar os keypoints, suas posições são refinadas usando o método proposto por [28] . O método usa a resposta da função $H(x, y, s)$, ou seja, o Hessiano com suas escalas, expandindo a mesma em série de Taylor e fazendo

\footnotetext{
${ }^{1}$ Imagem integral é uma estrutura de dados para cálculo eficiente da soma de pixels em uma área retangular. Cada pixel da imagem integral contém a soma dos pixels a esquerda e acima,incluindo o próprio pixel da imagem original
} 
Utilizando reconstrução 3D densa para odometria visual baseada em técnicas de structure from motion

o resultado igual a zero(ponto extremo):

$$
H(x)=H+\frac{\partial H}{\partial x}^{T} x+\frac{1}{2} x^{T} \frac{\partial^{2} H}{\partial x^{2}} x=0
$$

com solução

$$
\hat{x}=-\frac{\partial^{2} H^{-1}}{\partial^{2} x} \frac{\partial H}{\partial x}
$$

As derivadas são calculadas por diferenças finitas no espaço da função $H(x, y, s)$ e $\hat{x}$ é o novo valor interpolado para o keypoint.

$$
\sigma=2 k
$$

$$
\sigma=4 k
$$

$$
\sigma=\frac{3}{2} k
$$

$$
\begin{aligned}
& \sigma=2 k \\
& \sigma=8 k \\
& \sigma=4 k
\end{aligned}
$$

Figura 3.6: Vizinhos para non-maximum suppression, 3 oitavas com suas escalas
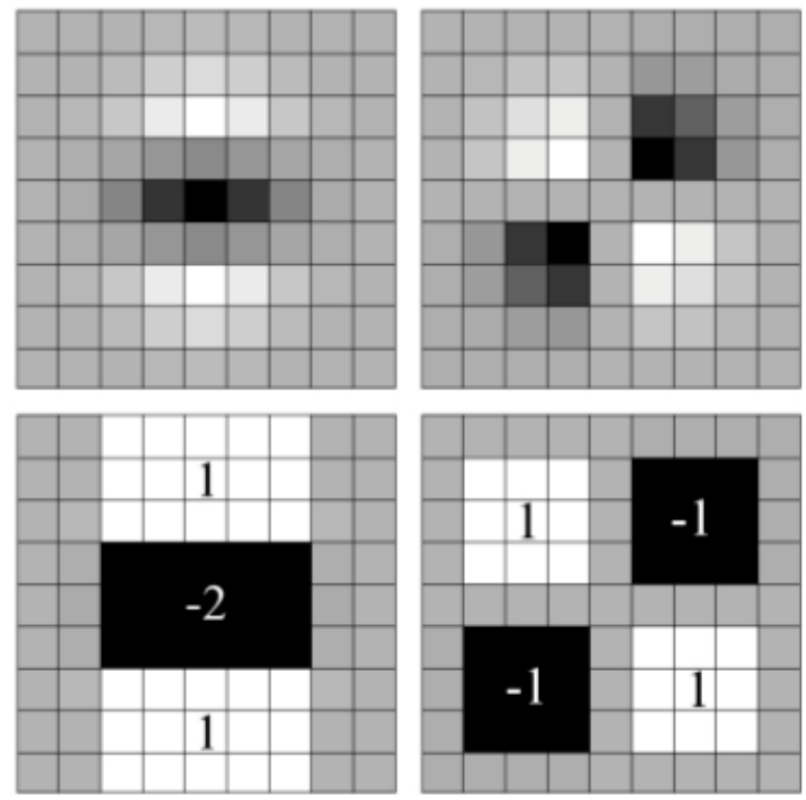

Figura 3.7: Aproximações $L_{y y}$ e $L_{x y}$ conhecidas como $D_{y y}$ e $D_{x y}$, usando conjuntos de filtros de caixa com $s=1.2$ 


\section{7}

\section{Kinect Fusion}

O Kinect Fusion permite a reconstrução 3D densa de uma cena interna em tempo real com uso de uma câmera RGBD e uma GPU. O método é resistente à pequenas variações de movimento de objetos da cena, podendo atualizar a reconstrução com a nova configuração da mesma. O método fornece uma odometria de alta precisão, um modelo 3D baseado em voxels e mapas de profundidade ${ }^{2}$ de alta qualidade. O pipeline do Kinect Fusion pode ser descrito nas seguintes etapas[10]

- Obter o mapa de profundidade, suavizar o mapa preservando as arestas e calcular as normais para cada ponto.

- Estimar a pose do novo mapa de profundidade.

- Atualizar o volume global com o novo mapa de profundidade.

- Gerar um mapa de profundidade por raycast utilizando uma predição para próxima pose e usar esse mapa para calcular a próxima pose.

\subsection{1}

\section{Processando o mapa de profundidade}

O objetivo desta etapa é criar um conjunto de pontos 3D definidos como $V_{k}$ e as normais $N_{k}$ na coordenada da câmera, dispostos num mapa 2D $U$ como no mapa de profundidade original.

O mapa de profundidade vindo do Kinect é bastante ruidoso sendo necessário aplicar o filtro bilateral[29] que suaviza o mesmo mas ao mesmo tempo mantém as arestas. Pequenos furos no mapa original são preenchidos com este filtro e o mesmo é fundamental para melhorar a qualidade do cálculo das normais. Em seguida os pontos podem ser calculados pela equação:

$$
v_{i}(u)=D(u) K^{-1} u
$$

onde $K$ é a matriz de parâmetros intrínsecos da câmera infravermelha do Kinect e $D$ o valor da profundidade deste pixel. A equação é o resultado da multiplicação da equação(3.2.3) por $K^{-1}$ com $g$ igual a identidade, já que o ponto está na coordenada da câmera. Já as normais $n_{i}$ são calculados com o produto vetorial entre as diferenças finitas dos pixels vizinhos nas direções $x \mathrm{e}$ $y$.

\footnotetext{
${ }^{2}$ Mapas de profundidade são imagens que contém a distância das superfícies de uma cena para determinado ponto de vista
} 


\subsection{2}

\section{Estimando a Pose}

Nesta etapa é estimada a pose utilizando o mapa de profundidade gerado pelo raycast entre a pose anterior e a atual. O cálculo dessa transformação é feito com uma variação do ICP conhecida como Point to Plane Error, utilizando a função de custo:

$$
\sum_{u}\left(T v_{i}(u)-v_{i-1}^{g}(u) \cdot n_{i-1}^{g}\right)^{2}
$$

sendo $T$ a transformação a ser achada e $u$ os pontos $2 \mathrm{D}$ correspondentes entre o mapa de profundidade atual e anterior; $v_{i-1}^{g}(u)$ é o ponto $2 \mathrm{D}$ do mapa anterior transformado para coordenada global com a pose anterior e $n_{i-1}^{g}$ a normal do mapa anterior. Supõe-se uma variação pequena entre um frame e outro e deste modo a transformação de corpo rígido $T_{i}=\left.T_{i-1} \exp (\xi)\right|_{\xi=0}$ pode ser escrita com a aproximação do mapa exponencial ao redor de zero com a matriz:

$$
\left[\begin{array}{cccc}
1 & \omega_{3} & -\omega_{2} & v_{1} \\
-\omega_{3} & 1 & \omega_{1} & v_{2} \\
\omega_{2} & -\omega_{1} & 1 & v_{3} \\
0 & 0 & 0 & 1
\end{array}\right]
$$

A equação normal do problema linearizado é reduzida em GPU. O sistema linear resultante é calculado em CPU com a fatoração Cholesky. Finalmente a transformação é calculada com $T_{i-1} \exp (\omega, v)=T_{i}$.

A associação dos pixels entre os mapas de profundidade é feita transformando o ponto $3 \mathrm{D} v_{i-1}^{g}$ com a transformação para coordenadas da câmera atual dada por $T_{i}^{-1}$. O ponto é projetado e verifica-se se o mesmo pertence ao frustum de visão. Caso seja, é calculada a distância entre a coordenada global do ponto $v_{i}^{g}$, que possui a coordenada $2 \mathrm{D}$ da projeção do ponto anterior, com $v_{i-1}^{g}$. O ângulo entre as normais de ambos os pontos também é calculado. De posse dos dois valores verifica-se se estão abaixo de um limiar e a correspondência entre os pontos com mesma coordenada 2D pode ser estabelecida. A interação entre a correspondência de pontos e o cálculo da pose via ICP é repetida até a precisão desejada.

\subsection{3}

\section{Integração Volumétrica}

Após calcular a pose global, os pontos do mapa de profundidade (não processados com filtro bilateral) são convertidos para uma coordenada global. 
O Kinect Fusion usa um grid 3D denso para integrar os mapas de profundidade medidos, conhecido como TSDF(Truncated Surface Distance Function). O TDSF é subdivido uniformemente em um conjunto de voxels com uma certa quantidade por eixo. A quantidade e o volume físico que um voxel possui define a resolução do volume reconstruído.

Os valores dos voxels são calculados percorrendo cada voxel do grid e projetando-os na pose atual. Caso esteja no frustum de visão o valor é atualizado com a seguinte formula:

$$
\begin{aligned}
s d f_{i} & =\left\|t_{i}-v^{g}\right\|-D_{i}(p) \\
t s d f_{i} & = \begin{cases}\min \left(1, s d f_{i} / t_{\max }\right) & \text { se } \quad s d f_{i}>0 \\
\max \left(-1, s d f_{i} / t_{\min }\right) & \text { senão }\end{cases} \\
w_{i} & =\min \left(w_{\max }, w_{i-1}+1\right) \\
t s d f^{\text {med }} & =\frac{t s d_{i-1} w_{i-1}+t s d_{i} w_{i}}{w_{i-1}+w_{i}}
\end{aligned}
$$

A primeira equação mede a distância do voxel com a profundidade medida(superfície física), consultando o mapa de profundidade com a projeção do voxel. $D_{i}(p)$ é o valor medido da projeção, $\left\|t_{i}-v^{g}\right\|$ é a distância do voxel $v^{g}$ para o centro de projeção atual dado por $t_{i}$ (translação da pose atual), $t s d f_{i}$ é o valor truncado por uma constante e $t s d f^{\text {med }}$ a média deste valor ao longo do tempo. Na figura 3.8 há uma ilustração do preenchimento dos voxels, a superfície implícita está indicada em vermelho.

\subsection{4}

\section{Raycast}

Nesta etapa é gerada uma nuvem de pontos de alta qualidade, utilizando o volume reconstruído. Este conjunto de pontos é gerado pelo raycast por pixel do volume TSDF. O raycast procede da seguinte maneira: para cada pixel $u$ do frustum de visão atual, é calculada a direção do raio pela diferença da retro-projeção do pixel $u$ com profundidade 0 e 1 (Algoritmo 1).

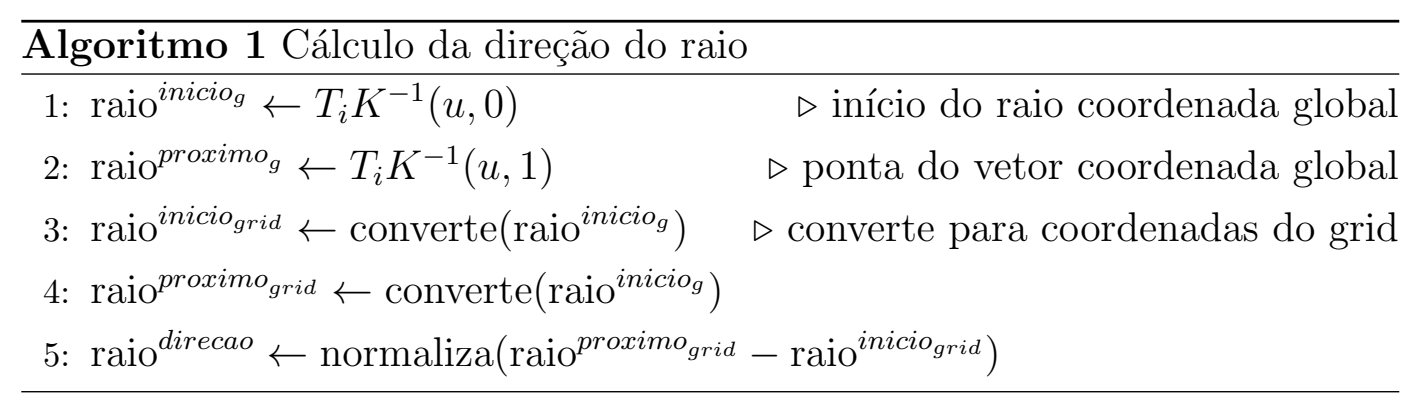




\begin{tabular}{|c|c|c|c|c|c|c|c|c|c|}
\hline-0.9 & -0.4 & -0 & 0.2 & 0.9 & 1 & 1 & 1 & 1 & 1 \\
\hline-1 & -0.9 & -0.2 & 1 & 0.5 & 0.9 & 1 & 1 & 1 & 1 \\
\hline-1 & -0.9 & -0.3 & 0. & 0.2 & 0.8 & 1 & 1 & 1 & 1 \\
\hline-1 & -0.9 & -0.4 & 0 & 0.2 & 0.8 & 1 & 1 & 1 & 1 \\
\hline-1 & -1 & -0.8 & -0.1 & 0.2 & 0.6 & 0.8 & 1 & 1 & 1 \\
\hline-1 & -0.9 & -0.3 & -0 & 0.3 & 0.7 & 0.9 & 1 & 1 & 1 \\
\hline-1 & -0.9 & -0.4 & 0 & 0.3 & 0.8 & 1 & 1 & 1 & 1 \\
\hline 0.9 & -0.7 & -0.5 & 0 & 0.4 & 0.9 & 1 & 1 & 1 & 1 \\
\hline-0.1 & 0.5 & 0.0 & 0.4 & 1 & 1 & 1 & 1 & 1 \\
\hline 1 & 1 & 1 & 1 & 1 & 1 & 1 & 1 & 1 & 1 \\
\hline
\end{tabular}

Figura 3.8: Representação do volume TSDF. Cada elemento do grid representa um voxel; a superfície está implicitamente representada pelo zero-crossing onde há a troca do sinal do valor TSDF. Os valores TSDF aumentam em módulo com a distância da superfície; valores negativos estão atrás e positivos na frente.

O raio deve marchar com um passo suficiente para atingir o próximo voxel e o passo pode ser acelerado com o tamanho da constante de truncamento. Achando um voxel com valor menor que zero o passo é ajustado para atingir o próximo, garantindo que seja encontrado a troca de sinal do valor TSDF, achando a superfície implícita. Ao cruzar a superfície implícita, a posição do zero é interpolada linearmente entre o voxel atual e o anterior. O cálculo da normal é feito com a derivada numérica entre as diferenças finitas dos valores TSDF. 


\section{4}

\section{Método Proposto}

O método consiste em dois blocos: o primeiro, a construção de um mapa off-line usando a reconstrução densa e o segundo a odometria em tempo real utilizando este mapa com keypoints/descritores esparsos.

\section{1}

\section{Mapa off-line}

No Kinect há duas câmeras, uma infravermelha que é usada para gerar o mapa de profundidade e a RGB. As câmeras estão rigidamente acopladas, ou seja há uma transformação de corpo rígido que leva uma pose da câmera RGB para câmera IR. Deste modo é possível usar a pose dada pela odometria do Kinect Fusion, por exemplo para projetar um ponto $3 \mathrm{D} X_{w}$ dado na coordenada do mundo, na câmera RGB. Usando a pose atual fornecida pelo Kinect Fusion $T_{w}^{i r}$, que leva um ponto na coordenada do mundo para coordenada da câmera IR, concatenada com a pose relativa entre as câmeras $T_{i r}^{r g b}$ é possível projetar um ponto $X_{w}$ na câmera RGB.

$$
x=K_{r g b} \pi_{o} T_{i r}^{r g b} T_{w}^{i r} X_{w}
$$

\subsection{1}

\section{Criando Mapa}

Utilizando o Kinect Fusion é feita uma reconstrução conforme os passos descritos na seção 3.7. O Kinect Fusion funciona a 30FPS, mesma taxa de quadros das câmeras do Kinect, portanto é possível calcular uma pose para cada quadro capturado. Com essas informações, mais o stream RGB (figura 4.1) é construído um mapa de keyframes constituído de um conjunto de keypoints, descritores e uma pose. Esse conjunto será usado para o cálculo da odometria na próxima etapa. O início do processo começa lendo o stream das câmeras IR e RGB sequencialmente, (algoritmo 2, linha 2 e 3). Após é executado o pipeline do Fusion (linha 4). Verifica-se se o tracking é válido ( convergência dado pela API do Kinect Fusion), se o intervalo de tempo entre a captura das duas imagens é inferior a um limiar e finalmente se houve um movimento com distância maior que $10 \mathrm{~cm}$ ou ângulo maior que 10 graus entre a última imagem armazenada no buffer e a atual. Após isso, é feito outro raycast do volume usando a pose da câmera RGB e seus parâmetros intrínsecos, com 


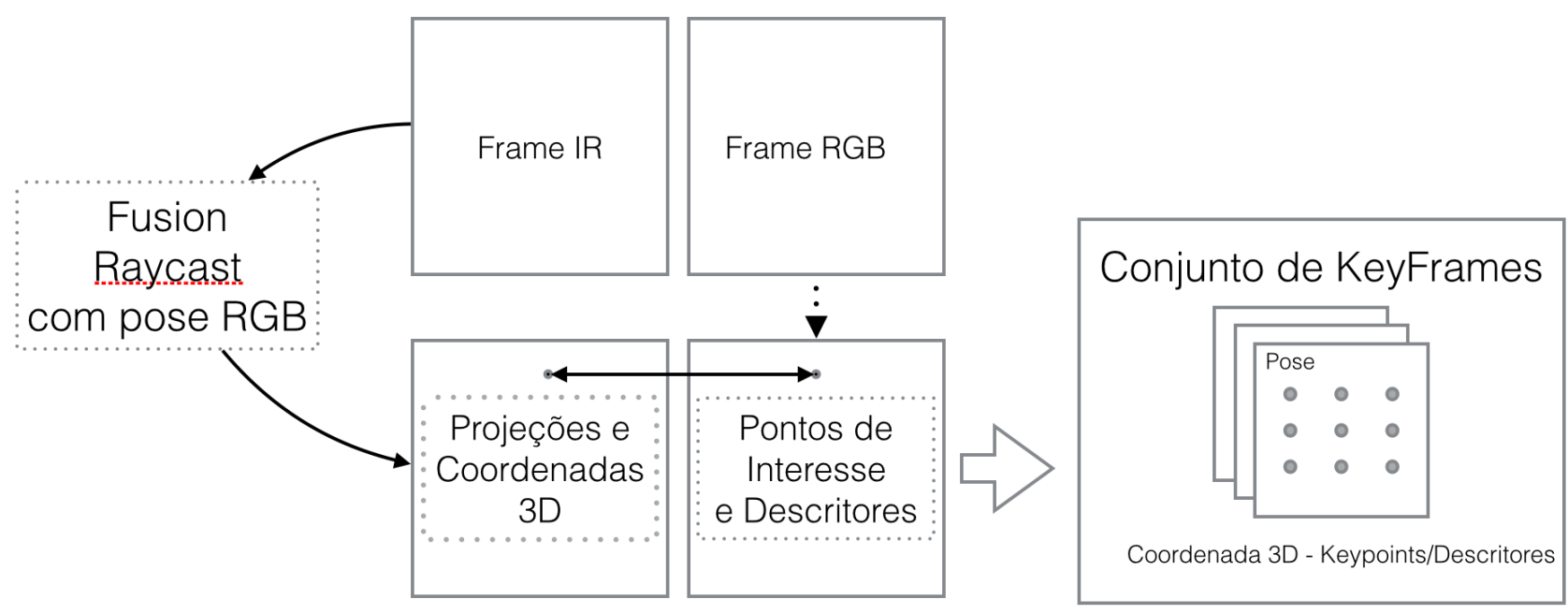

Figura 4.1: Fluxo da construção do mapa off-line

esses dados é gerada uma imagem onde os pixels possuem a coordenada 3D do mundo, (linha 7). As imagens RGB e 3D são guardadas num buffer. Após um determinado número de quadros o processo é finalizado e o buffer é gravado em disco. Posteriormente, para cada conjunto de imagens 3D e RGB são gerados seus respectivos pares de keypoints SURF e descritores FREAK.

Os keypoints SURF e descritores FREAK, linhas 12 e 13, são calculados utilizando a biblioteca OpenCV[25]. O detector SURF do OpenCV segue a descrição da seção 3.6. O cálculo do non max suppresion é feito comparando todos vizinhos pixel por pixel de forma simples, embora haja algoritmos de maior desempenho. Isso permite que a implementação seja trivialmente paralelizável. Os parâmetros utilizados no cálculo dos keypoints são: valor acima 300 para determinante do Hessiano, 4 oitavas e duas escalas por oitava. A implementação do descritor FREAK utiliza o tamanho dos keypoints, (no caso do keypoint SURF, o tamanho do kernel utilizado na escala onde o keypoint foi encontrado), para ajustar a posição e área de amostra (seção 3.5.1). A escala na área da amostra permite que o descritor FREAK seja resistente a operações de escala. Outra optimização é a substituição dos kernel gaussianos, por uma média dos pontos na área da amostra usando imagem integral. 
Utilizando reconstrução 3D densa para odometria visual baseada em técnicas de structure from motion

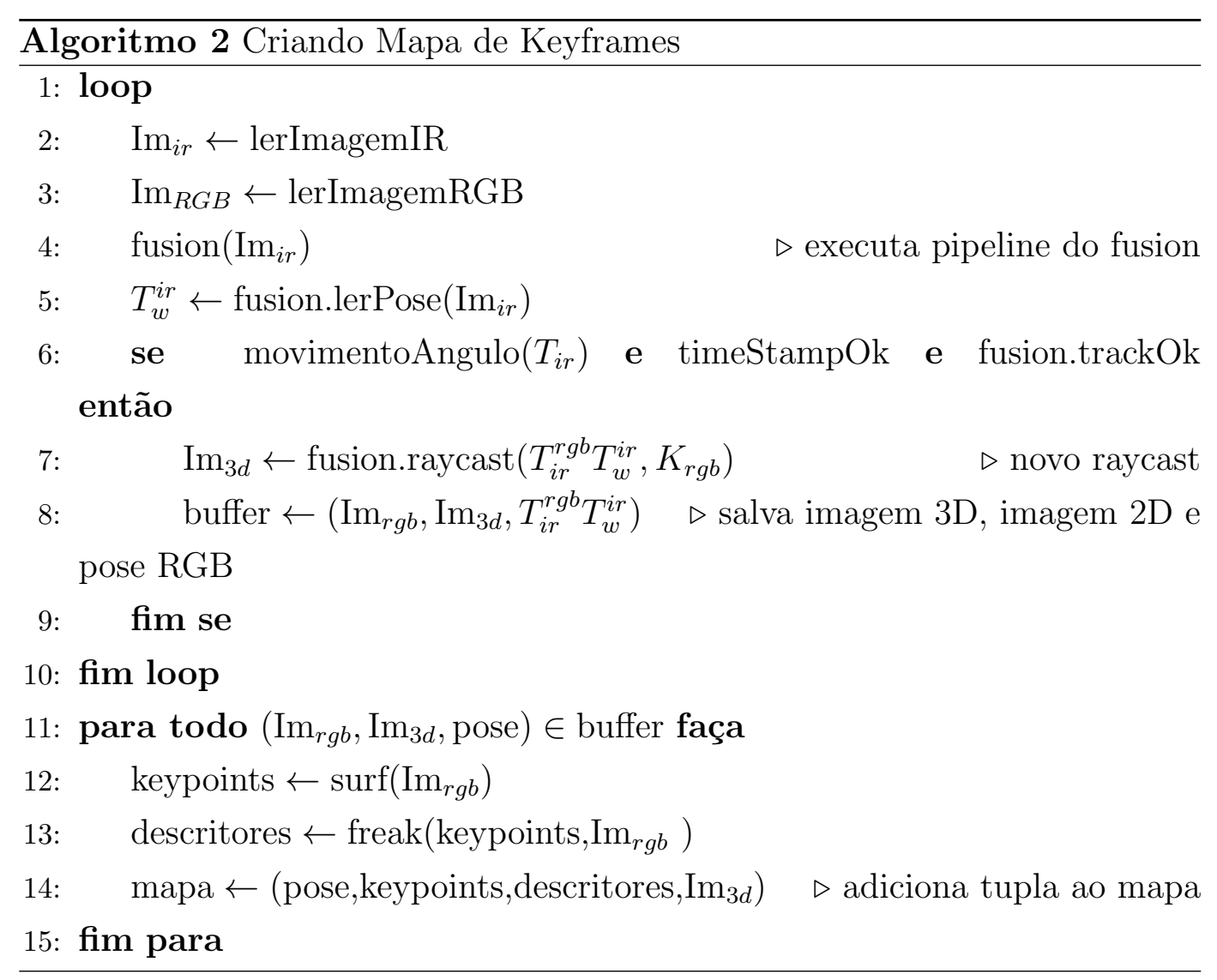

\section{2}

\section{Odometria em Tempo Real}

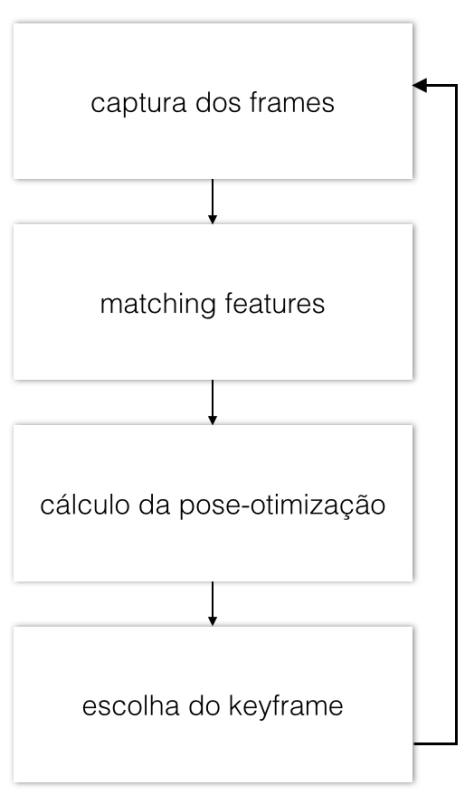

Figura 4.2: Fluxo do cálculo da odometria 
A odometria visual fornece uma pose $g(R, T)$ utilizando o stream da câmera RGB e o mapa de keyframes. A pose é calculada nas seguintes etapas (figura 4.2)

- Ler imagem do stream RGB (algoritmo 3, linha 2)

- Calcular os keypoints SURF e descritores FREAK; buscar os descritores similares do keyframe atual e imagem e criar o conjunto dos pontos $2 \mathrm{D}$ e 3D (linhas 3-5)

- Calcular a pose minimizando o erro de reprojeção dos pontos 3D na imagem atual (linha 6)

- Localizar keyframe mais próximo seguindo uma métrica entre ângulo e distância da pose atual com a pose calculada (linha 7)

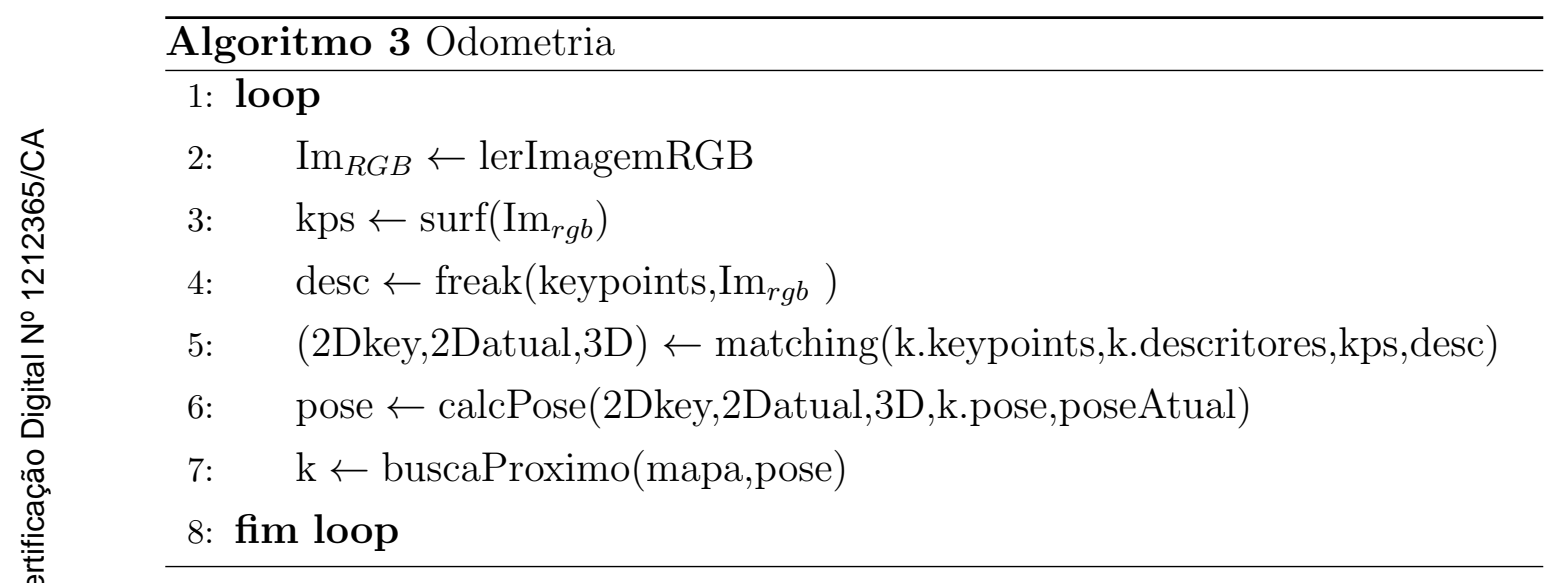

\subsection{1}

\section{Matching}

Nesta etapa é feita a associação entre os descritores do quadro atual e os descritores do keyframe. Primeiro são calculados os keypoints SURF (algoritmo 3 linha 3) e após os descritores FREAK, linha 4. Em seguida é feita uma busca dos vizinhos mais próximos $(\mathrm{NN})$ utilizando como métrica a distância de Hamming, que é dada por $\operatorname{soma}\left(\operatorname{xor}\left(s_{1}, s_{2}\right)\right)$ sendo $s_{1}$ e $s_{2}$ duas strings binárias, xor o ou exclusivo e soma conta os números 1 na string resultante.

A busca é feita por força bruta comparando cada descritor do conjunto do quadro atual com o conjunto dos descritores keyframes, selecionando o descritor com menor distância para cada par. Apesar de ser feita por força bruta foi utilizada a classe BFMatcher do OpenCV que possui algumas optimizações. O cálculo das distâncias entre as combinações é paralelizado, embora a busca pelo menor par continue sequencial. O cálculo das distâncias de Hamming utiliza as instruções SIMD quando disponível, utilizando xor com várias palavras de 
32 ou 64 bits ao mesmo tempo, dependendo da arquitetura. A soma também é feita com instruções SIMD contando o número de 1 em várias palavras ao mesmo tempo. Uma estrutura hierárquica não cabe para este problema devido a dimensão do descritor ser 512. São possíveis apenas buscas aproximadas como FLANN[30], sem ganho significativo de desempenho para quantidade dos keypoints normalmente encontrada pelo detector SURF.

Após a busca pelo vizinho mais próximo é feita uma filtragem selecionando as correspondências mais fortes, verificando se a menor distância para o descritor $i$ do conjunto $A$ é o descritor $j$ do conjunto $B$, e se essa relação é válida no sentido oposto (figura 4.3). Esse cálculo é feito de forma aproximada percorrendo as tuplas calculadas da busca nn(A,B), para cada tupla $\left(a_{i}, b_{j}, d\right)$ atualizar a tupla $\left(b_{j}, a_{k}, d \min \right) \operatorname{com}\left(b_{j}, a_{j}, d\right)$ caso $d<d m i n$. As tuplas resultantes formadas contém os pares filtrados. A figura 4.3 exemplifica o processo com distância euclidiana, mas o mesmo exemplo é válido para a distância de Hamming que satisfaz os axiomas de distância, notadamente no exemplo a simetria $d(a, b)=d(b, a)$.

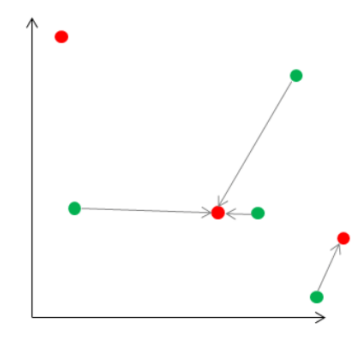

(a) nn(verde, vermelho)

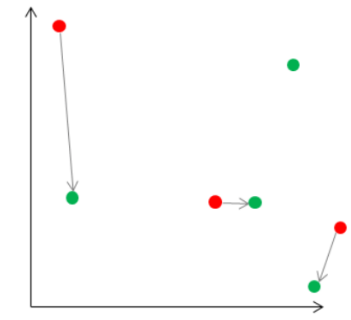

(b) nn(vermelho,verde)

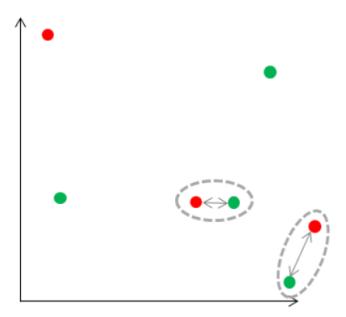

(c) cross

Figura 4.3: Procedimento de filtragem das correspondências mais fortes

\section{2 .2}

\section{Cálculo da Pose}

O cálculo da pose é feito minimizando o erro de reprojeção dos pontos 3D encontrados no matching e projetados na imagem atual. O residual é dado por:

$$
r_{i}=\pi\left(X_{i}\right)-x_{i}
$$

onde $\pi$ é a projeção (seção 3.2.4), $X_{i}$ a coordenada 3D e $x_{i}$ o pixel encontrado no quadro atual (este residual fornece duas equações). Esse é um problema de mínimos quadrados não linear contendo outliers, resolvido de forma semelhante como na seção 3.4.3. A projeção pode ser parametrizada usando o espaço tangente da transformação de corpo rígido, e supondo uma pequena 
transformação $\xi \approx 0$ em relação a uma pose anterior $G(R, T)$. Esta suposição permite calcular a jacobiana da projeção $\pi$ de modo simples com a fórmula como descrito em [31].

$$
\begin{gathered}
\frac{\partial \pi\left(e^{\hat{\xi}} \oplus G \oplus X\right)}{\partial \xi}=\left.\left.\frac{\partial \pi\left(X^{\prime}\right)}{\partial X^{\prime}}\right|_{X^{\prime}=G \oplus X=g} \frac{\partial e^{\hat{\xi}} \oplus G \oplus X}{\partial \xi}\right|_{\xi=0} \\
\left(\begin{array}{ccc}
f_{x} / g_{z} & 0 & -f_{x} g_{x} / g_{z}^{2} \\
0 & f_{y} / g_{z} & -f_{y} g_{y} / g_{z}^{2}
\end{array}\right)\left(\begin{array}{ll}
I_{3} & -\hat{g}
\end{array}\right)
\end{gathered}
$$

A simplificação $\xi=0$ não é sempre o caso do problema atual. $\mathrm{O}$ uso de um descritor robusto permite que o matching funcione com diferença considerável entre as poses e a parametrização deve levar em conta esta caraterística. Deste modo a projeção $\pi$ é parametrizada com a equação:

$$
K\left(e^{\hat{\omega}} X+T\right)=X_{\pi} \quad x=X_{\pi}^{1} / X_{\pi}^{3} \quad y=X_{\pi}^{2} / X_{\pi}^{3}
$$

com a variável $\mathbf{x}=\left(\omega_{1}, \omega_{2}, \omega_{3}, t_{1}, t_{2}, t_{3}\right)$

Este problema é resolvido com auxilio da biblioteca Ceres Solver[32], com uso de derivadas automáticas[33] e com o método Levenberg-Marquardt(LM) variação do Gauss-Newton, que é mais robusto para soluções iniciais mais distantes. O método LM aumenta a matriz Hessiana com uma matriz diagonal $D$, fazendo os valores da diagonal variarem entre o método de Gauss-Newton $D=0$ e o gradiente descendente $D=\infty$, de acordo com a solução encontrada no momento. A biblioteca Ceres-Solver implementa o LM como descrito em [34] com algumas variações, sendo as principais o cálculo da matriz diagonal com escala e o suporte às funções de perda, algoritmo 4. A qualidade da solução atual, calculada na linha 11, é o custo da solução atual menos a anterior, sobre a diferença estimada pelo modelo linearizado. O valor linearizado (denominador) sempre é positivo, portanto, caso $\varrho<0$ (linha 7) o custo aumentou e o raio $\mu$ caminha na direção gradiente descendente (linha 19). Caso $\varrho>0$ o raio é ajustado de acordo com a qualidade encontrada (linha 17). O custo da solução $F(x)$ é dado pela soma do quadrado dos residuais $F(x)=\frac{1}{2} r(x)^{T} r(x)$. A matriz diagonal $D$ (linha 6 ) é calculada como a raiz do produto do raio $\mu$ com o valor da norma da coluna da jacobiana, sendo o valor da coluna $i$ dado por $J_{i}, D_{i}=\mu\left\|J_{i}\right\|$. A escala no residual e jacobiana são calculadas usando a função de perda $\rho\left(F_{i}(x)=r_{i}(x)^{2}\right)$. A função que é usada na escala é a derivada $\rho^{\prime}\left(F_{i}(x)\right)$ e o residual e a jacobiana são multiplicados por $r_{k}=\sqrt{\rho^{\prime}\left(F_{k}\right)} r_{k}$ e $J_{k}=\sqrt{\rho^{\prime}\left(F_{k}\right)} J_{k}$ (linha 2 e 14 ), sendo $r_{k}$ valor $k$ do residual e $J_{k}$ linha $k$ da 
Jacobiana. A função de perda utilizada é Tukey's biweight[35], com seguinte comportamento:

$$
\rho^{\prime}(x)=\left\{\begin{array}{l}
x\left(1-\frac{x^{2}}{c^{2}}\right) \quad \text { se } \quad x<c \\
0 \text { se } \quad x>c
\end{array}\right.
$$

Esta função suprime os outliers. Como não é convexa, um novo mínimo local difere do valor ótimo. O valor ótimo de $c$ é 4,68 para residuais com variância $\sigma=1$; deste modo deve ser feita uma escala para o residual $r_{i} / \sigma$. $\mathrm{O}$ valor de $\sigma$ é aproximado por MAD(r)/0.6745 sendo MAD median of absolute deviation calculado por:

$$
\operatorname{MAD}=\frac{1}{n} \sum_{i}^{n}\left|x_{i}-\operatorname{mediana}(x)\right|
$$

O valor de $\sigma$ é calculado apenas uma vez após a convergência. O sistema linear que calcula o passo $\Delta$ (linha 6) é chamado sistema linear regularizado aumentado, na forma:

$$
\left(\begin{array}{l}
J \\
D
\end{array}\right) \Delta=\left(\begin{array}{c}
-r \\
0
\end{array}\right)
$$

O sistema resultante é resolvido por mínimos quadrados com decomposição QR. Fazendo $A=(J, D), \Delta=x$ e $b=(-r, 0)$ e decompondo $A=Q R$, chega-se ao sistema $R x=Q^{T} b ; x$ é calculado via retro-substituição. São usados como solução termos do tamanho original de $J$. Após a solução $x=\left(\omega_{1}, \omega_{2}, \omega_{3}, t_{1}, t_{2}, t_{3}\right)$ convergir, a parte devido a rotação é convertida para matriz por $e^{\hat{\omega}}$. A solução atual é usada como solução inicial para a próxima interação. Caso não haja convergência $x_{0}=\mathbf{0}$. 


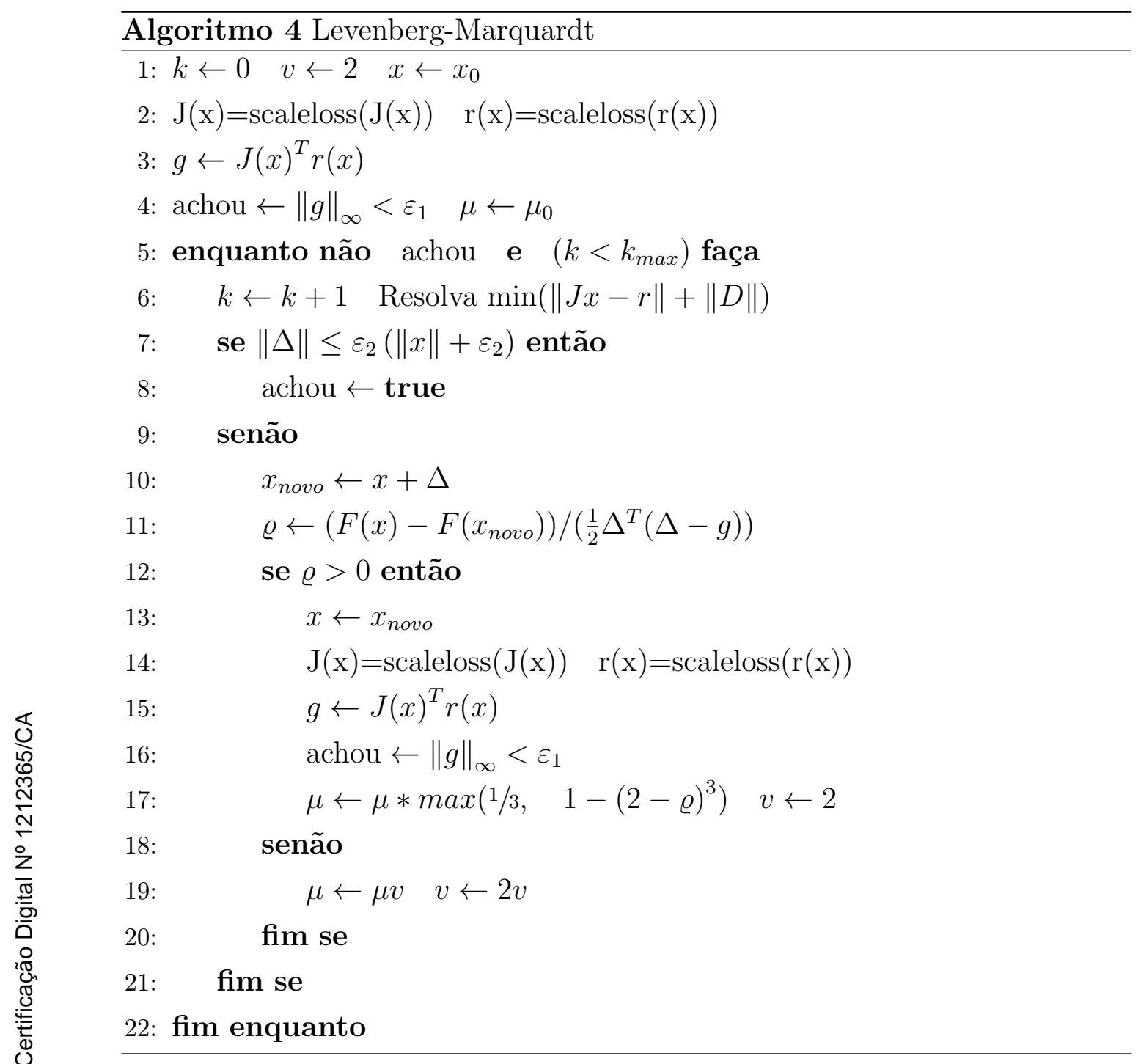

\subsection{3}

\section{Escolha do Keyframe}

O keyframe que será usado no matching é o que possui o valor mínimo da fórmula $(2-\cos (a))^{2} d$, onde d é a distância entre a origem da pose atual $P$ e keyframe $k_{i}$ e $a$ o ângulo entre as componentes $z$ (figura 4.4). As poses $\mathrm{P}$ e $P_{k}$ (pose do k-ésimo keyframe) levam as coordenadas do mundo para a câmera e podem ser vistas como matrizes de mudança de base ortonormal com mudança de origem:

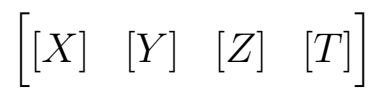

A componente $Z$ aponta para o centro de projeção (ver figura 3.2) e $T$ é a distância para origem da coordenada do mundo. O coseno do ângulo $a$ e a 
Utilizando reconstrução 3D densa para odometria visual baseada em técnicas de structure from motion

distância $d$ são dados por:

$$
\cos (a)=\frac{Z_{k} \cdot Z_{p}}{\left\|Z_{k}\right\|\left\|Z_{p}\right\|} \quad d=\left\|T_{k}-T_{p}\right\|
$$

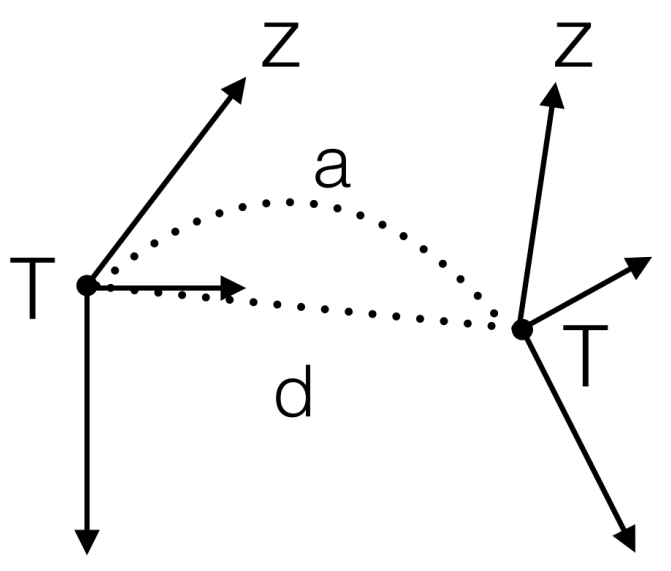

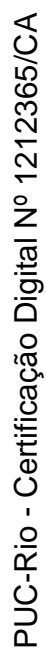

Figura 4.4: Ângulo e distância entre duas poses 


\section{5 \\ Resultados}

Neste capítulo é apresentada uma comparação do método proposto com a odometria calculada pelo Kinect Fusion e uma análise do desempenho.

\section{1 \\ Experimento}

O experimento realizado possui duas partes: a montagem do mapa e a captura de quadros e dados da odometria do Kinect Fusion para comparação com o método proposto.

O mapa foi feito utilizando os seguintes parâmetros para reconstrução do Kinect Fusion: resolução de 128 voxels por metro, com um volume de $512 \times 384 \times 512(X, Y, Z)$ voxels, resultando num volume de $4 \times 3 \times 4$ metros e resolução por voxel de 8x10x8 milímetros. A captura dos quadros utilizados na montagem do mapa foi feita a cada movimento de $15 \mathrm{~cm}$ entre os quadros ou ângulo de 10 graus, ambos medidos com base na odometria do Fusion. Como há apenas o critério da distância e ângulo para captura dos quadros, a captura manual procurou evitar que a câmera passasse pela mesma região várias vezes. O cálculo dos parâmetros intrínsecos das câmeras RGB e IR e da pose relativa entre ambas foi feito com MRPT[36].

Os quadros capturados para comparar a odometria diferem dos utilizados no mapa, e foram capturados de forma contínua a 20FPS com resolução $640 \times 480$ pixels. É gravada uma imagem $\operatorname{Im}_{i}$ e uma pose $P_{i}$ para cada interação do Fusion formando um conjunto de imagens e poses. Posteriormente utilizando este conjunto de imagens, é calculada uma pose $P_{i}^{\prime}$ de forma contínua para cada imagem $I m_{i}$ com o método proposto. A precisão da odometria é medida calculando-se a distância entre as poses $P_{i}$ e $P_{i}^{\prime}$ e o ângulo entre as mesmas. É utilizado o mesmo volume de reconstrução em ambas as etapas, portanto, estão no mesmo sistema de coordenadas. A taxa de 20FPS usada para testar o método proposto é inferior a taxa de 30FPS alcançada pelo Kinect Fusion durante a reconstrução. Este valor foi escolhido para testar um maior movimento entre dois quadros e também para representar um valor mais realista do desempenho atual do método com média de 19FPS para a cena 2 .

O manuseio do Kinect foi feito com apenas uma mão, evitando movimentos bruscos. 


\section{2}

\section{Cena 1}

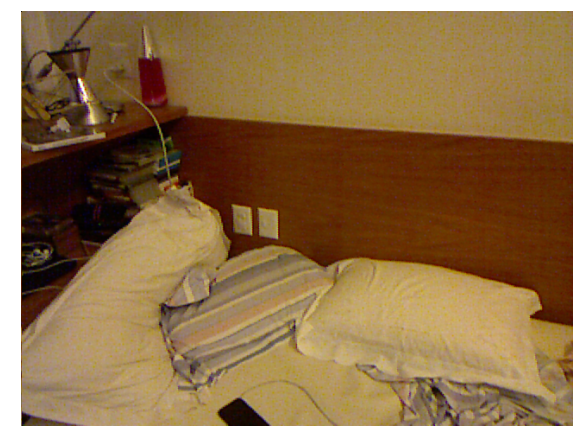

(a)

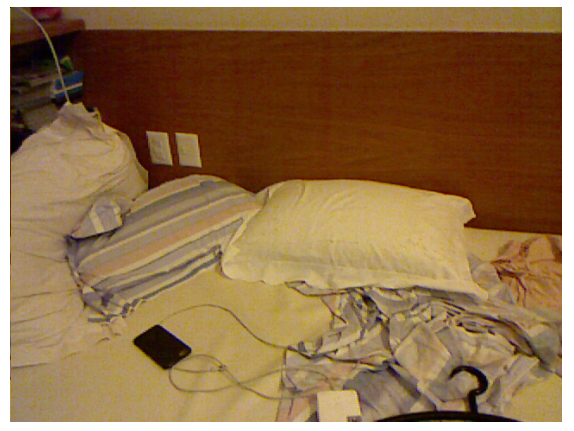

(b)

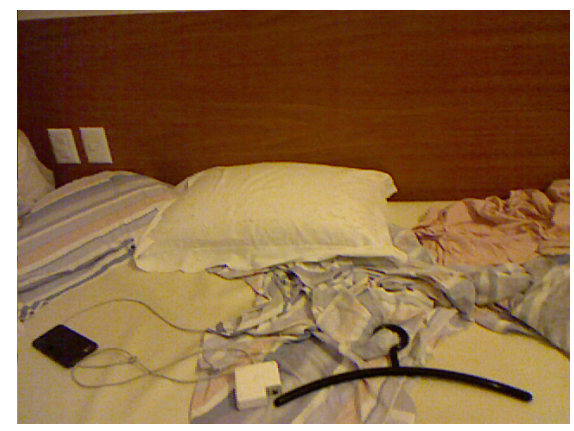

(c)

Figura 5.1: Cena 1

O primeiro teste, foi feito em quarto com luz artificial rico em texturas (funcionamento do matching) e variação de geometria (funcionamento do Kinect Fusion), ver figura 5.1. Durante o teste foram feitos poucos movimentos bruscos.

\subsection{1}

\section{Análise dos resultados}

Durante a fase de matching e criação do mapa o detector SURF achou uma alta quantidade de keypoints, média de 652 por quadro. Na figura 5.2 há uma visualização do matching mostrando, à direita, uma imagem de um keyframe e, à esquerda, um quadro onde é calculada a odometria. Os pontos brancos são os keypoints/descritores e as linhas as correspondências encontradas entre ambos. Na região do quadro quadriculado pode-se notar a presença de vários outliers.

Na figura 5.3 é mostrada a mediana do erro de reprojeção usado no cálculo da pose. A área sombreada é o intervalo entre mediana+MAD e mediana-MAD. Valores altos desses parâmetros indicam a presença de outliers. Embora haja vários picos desses valores, a distância e orientação para pose calculadas em 


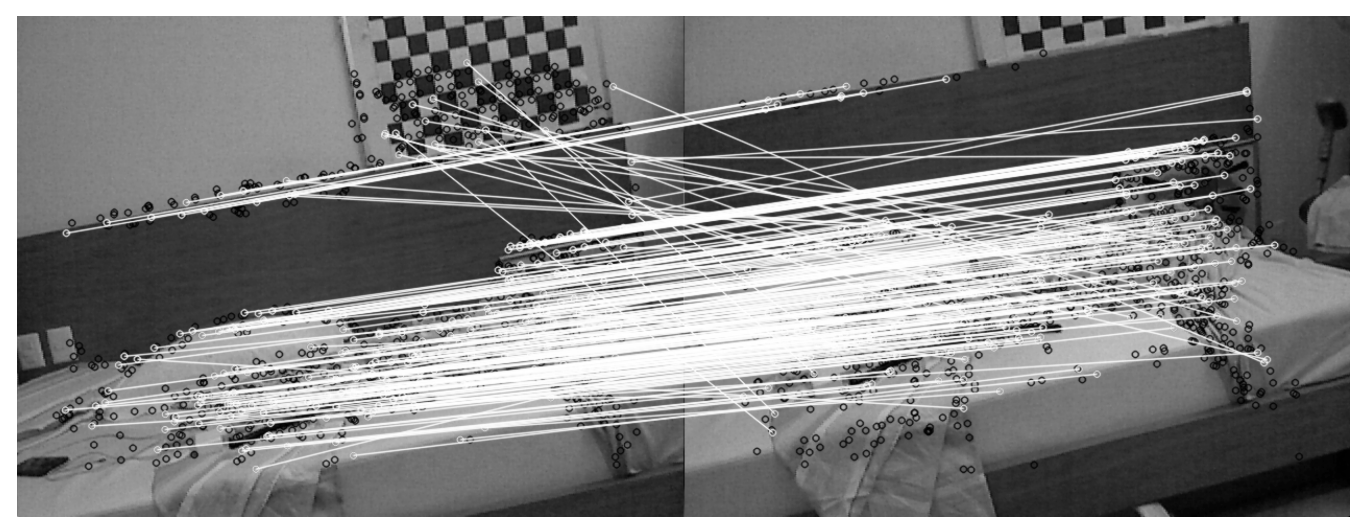

Figura 5.2: Outliers presentes no matching

relação ao Fusion se mantiveram, respectivamente, menor que 4cm (figura 5.4) e menor que 2 graus (figura 5.5) por todo o experimento. A função de perda conseguiu limitar a influência dos outliers. O parâmetro da função de perda justamente por essa grande variação na mediana foi mantido fixo. $\mathrm{O}$ uso de descritores robustos permite o cálculo da pose com ângulo de até 25 graus entre as componentes $Z$ do keyframe e a pose calculada.

Tabela 5.1: Estatística dos ângulos em relação Fusion, cena 1

\begin{tabular}{l|cccc}
\hline \hline & média & $\max$ & $\min$ & std \\
\hline pitch & 0,5 & 1,6 & 0 & 0,4 \\
yaw & 0,4 & 1,9 & 0 & 0,3 \\
roll & 0,2 & 0,9 & 0 & 0,2 \\
\hline
\end{tabular}

O valor máximo para a distância entre a pose calculada pelo Fusion e pelo método proposto foi $3,75 \mathrm{~cm}$ com mínimo de $0,14 \mathrm{~cm}$. O valor médio foi de $1,83 \mathrm{~cm}$ com mediana de $1,83 \mathrm{~cm}$ e desvio padrão de $0,67 \mathrm{~cm}$ (figura 5.4 ). A estatística para os dados dos ângulos (figura 5.5) está na tabela 5.1.

Na execução (tabela 5.2) o tempo dominante ficou com o detector SURF. Apesar de ser constante, o cálculo do Hessiano possui 41 operações aritméticas para o cálculo de um determinante $\operatorname{Det}(H)$ (figura 3.7) e é repetido em várias escalas para cada pixel (4 oitavas com 2 escalas por oitava).

Outra parte custosa é o non maximal supression com 26 comparações, no caso do keypoint ser um ponto de máximo em sua oitava, junto com a interpolação para ajuste da posição (resolução de um sistema linear 3x3). A quantidade de keypoints impacta diretamente o matching $O\left(n^{2}\right)$ e o cálculo da pose $O\left(m n^{2}\right)$ ( parte mais custosa do cálculo da pose é a resolução via mínimos quadrados com decomposição $\mathrm{QR}$ ), onde $m$ é a quantidade de 


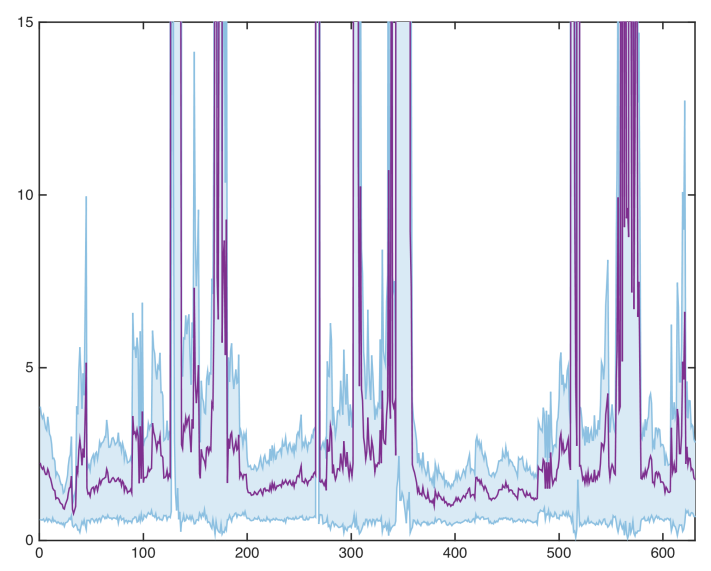

(a) detalhes

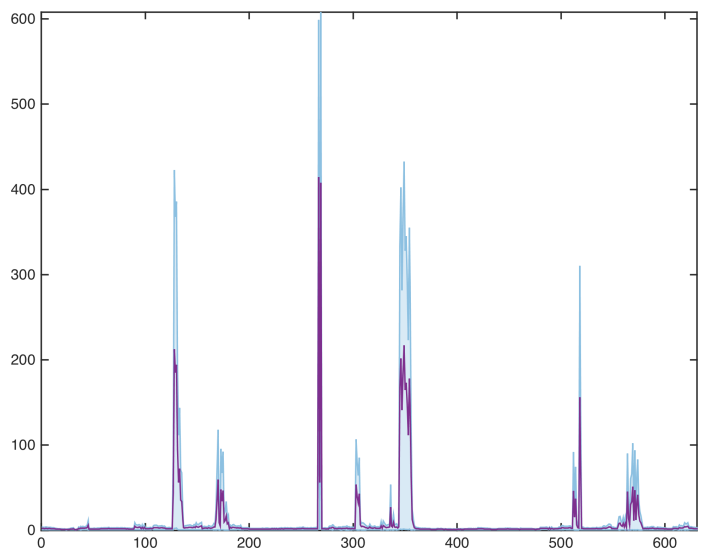

(b) visão geral

Figura 5.3: Eixo Y, mediana do erro de reprojeção em roxo. Área em ciano, valor da mediana limitada por MAD. Eixo X, imagens

Tabela 5.2: Tabela com tempo de execução dos componentes principais do método proposto

\begin{tabular}{l|cc}
\hline \hline LM & $3,94 \mathrm{~s}$ & $18,6 \%$ \\
SURF & $11,9 \mathrm{~s}$ & $56 \%$ \\
FREAK & $1,03 \mathrm{~s}$ & $4,6 \%$ \\
NN & $3,97 \mathrm{~s}$ & $19 \%$ \\
\hline Total & \multicolumn{2}{|c}{$21,2 \mathrm{~s}$} \\
FPS & \multicolumn{2}{|c}{29,8} \\
\hline *
\end{tabular}

parâmetros da jacobiana e $n$ a quantidade resultante de keypoints filtrados pela correspondência mais forte. O descritor FREAK embora tenha um custo 
Utilizando reconstrução 3D densa para odometria visual baseada em técnicas de structure from motion

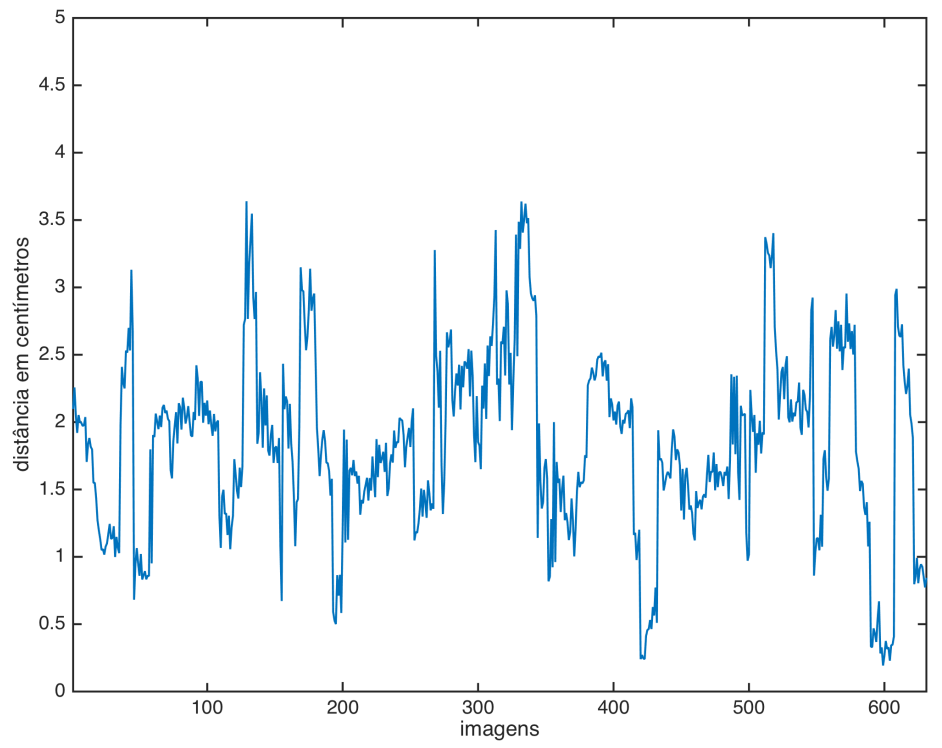

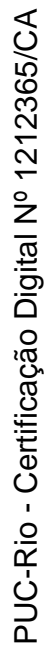

Figura 5.4: Distância em centímetros em relação ao Fusion

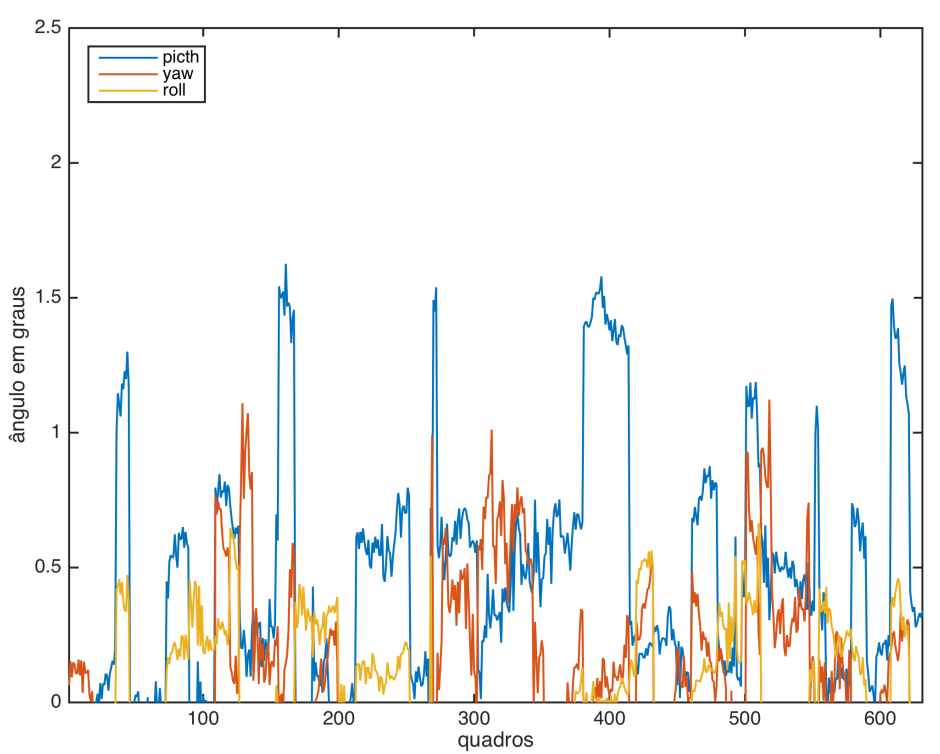

Figura 5.5: Ângulos de Euler sobrepostos da pose calculada em relação ao Kinect Fusion. Convenção: $\operatorname{roll}(\mathrm{X})-\operatorname{pitch}(\mathrm{Y})-\mathrm{yaw}(\mathrm{Z})$ 
Utilizando reconstrução 3D densa para odometria visual baseada em técnicas de structure from motion

maior por pixel, são 37 somas de área (figura 3.3) usando imagem integral mais as 512 diferenças das combinações (figura 3.4), o mesmo só é calculado para cada keypoint, menos de 700 por imagem.

Na figura 5.6 há uma visualização do experimento. Pontos brancos representam keypoints/descritores do mapa e a linha azul é trajetória da câmera calculada pelo Kinect Fusion. As setas verdes (eixo Z) e vermelha (eixo Y), dispostas na posição da pose (figura 3.2), representam a odometria calculada. 
Utilizando reconstrução 3D densa para odometria visual baseada em técnicas de structure from motion

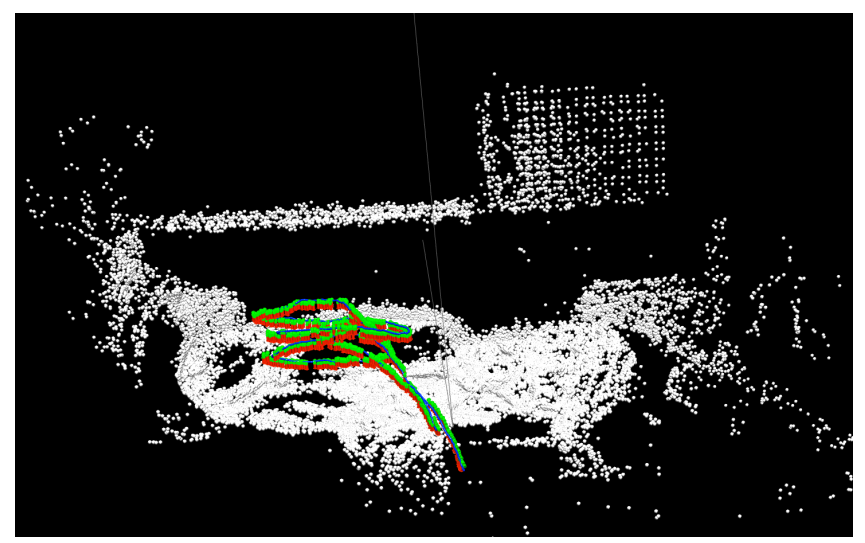

(a) visão geral

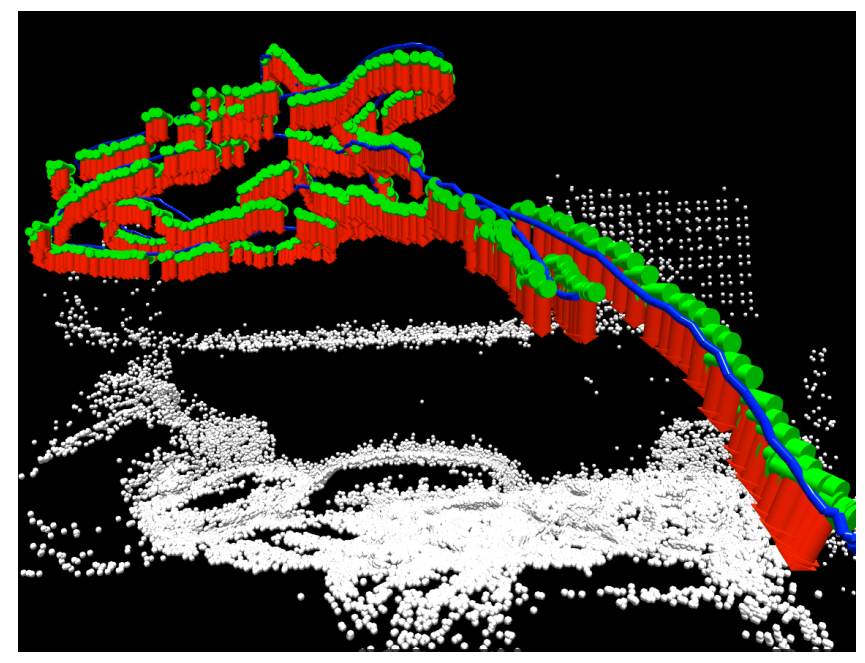

(b) vista lateral

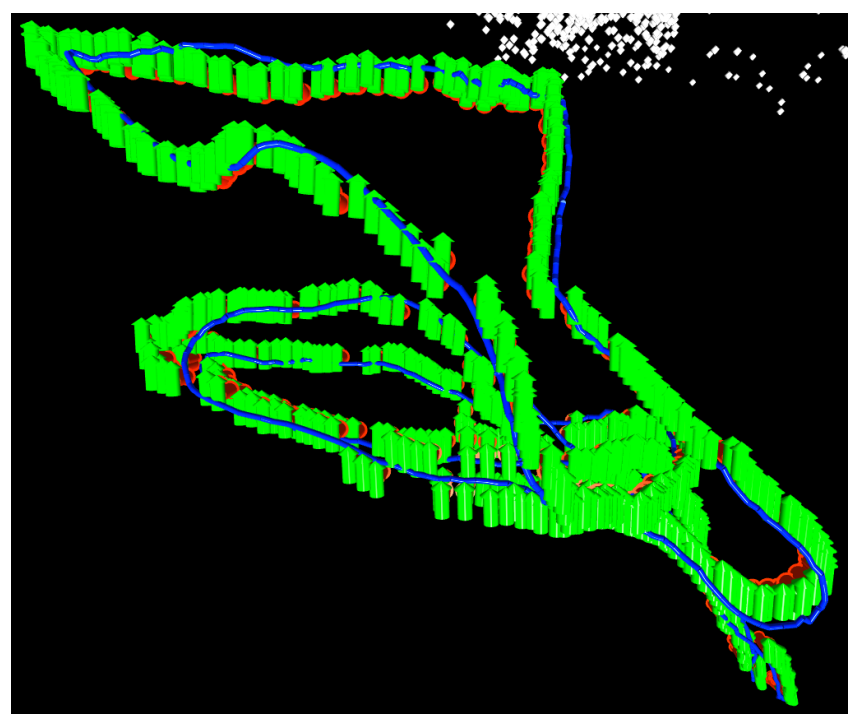

(c) vista de topo

Figura 5.6: Visualização 3D da odometria calculada (cena 1) 
Utilizando reconstrução 3D densa para odometria visual baseada em técnicas de structure from motion

\section{3}

\section{Cena 2}

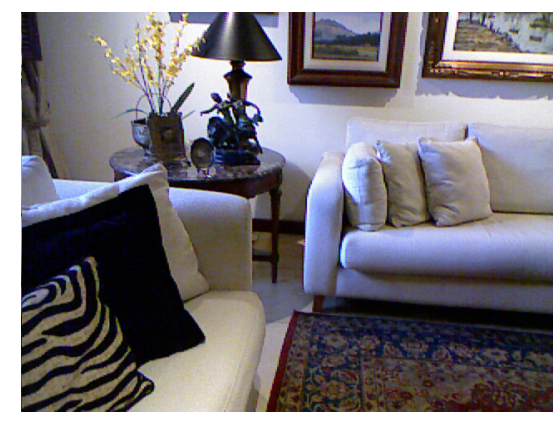

(a)

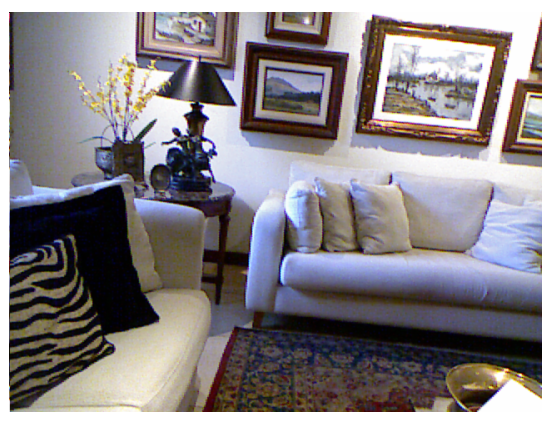

(b)

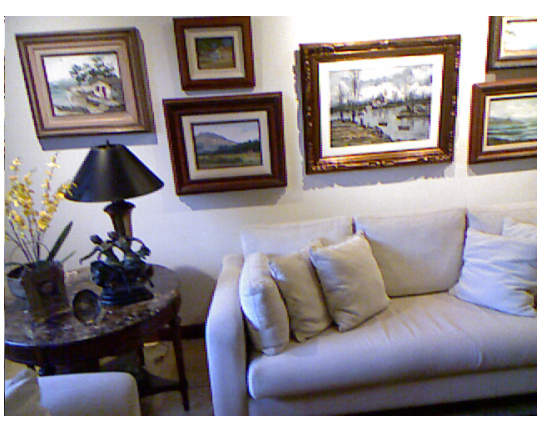

(c)

Figura 5.7: Cena 2

Na cena 2 mantivemos os requisitos para o funcionamento do método. A cena 2 representa um ambiente rico em textura e geometria (figura 5.7), que foi iluminado parcialmente com luz natural (horário próximo do por do sol) e focos de luz artificial.

\subsection{1}

\section{Análise dos resultados}

Tabela 5.3: Tabela com tempo de execução dos componentes principais do método proposto, cena 2

\begin{tabular}{l|cc}
\hline \hline LM & $4,12 \mathrm{~s}$ & $17,8 \%$ \\
SURF & $11,6 \mathrm{~s}$ & $50 \%$ \\
FREAK & $1,18 \mathrm{~s}$ & $5 \%$ \\
NN & $5,9 \mathrm{~s}$ & $25 \%$ \\
\hline Total & \multicolumn{2}{|c}{$23,2 \mathrm{~s}$} \\
FPS & \multicolumn{2}{|c}{21,2} \\
\hline \hline
\end{tabular}

${ }^{*}$ Quadros por segundo 
Neste experimento foi detectado um número maior de keypoints, 1400 em média, o que explica o tempo maior utilizado pelo detector SURF. São mais vezes chegando até ao final das comparações achando pontos de máximo e principalmente calculando o ajuste de posição do keypoint. Os outros fatores como dependem também da quantidade de keypoints tiveram um desempenho pior, resultando num FPS mais baixo (tabela 5.3). O experimento na cena 2 teve uma qualidade visivelmente pior do que na cena 1 . A piora na qualidade fica latente com os seguintes dados: o valor máximo para a distância em relação ao Fusion foi de 22,6cm com mínimo de 0,18. A média teve valor de 4,63 com mediana de $3,68 \mathrm{~cm}$ e desvio padrão de $3,80 \mathrm{~cm}$ (figura 5.8). A estática para os dados dos ângulos (figura 5.9), está na tabela 5.4. A piora na qualidade

Tabela 5.4: Estatística dos ângulos em relação Fusion, cena 2

\begin{tabular}{l|cccc}
\hline \hline & média & $\max$ & $\min$ & std \\
\hline pitch & 0,6 & 4,6 & 0 & 0,8 \\
yaw & 0,7 & 3,37 & 0 & 0,7 \\
roll & 0,5 & 2,2 & 0 & 0,3 \\
\hline
\end{tabular}

deve-se à performance do matching (figura 5.11), resultando erros maiores de reprojeção (figura 5.10). O parâmetro $\mu_{0}$ do $\operatorname{LM}\left(\mu_{0}=10^{4}\right)$ é sempre mantido alto, ou seja o método sempre começa na região de gradiente descendente, o que ajuda o método a voltar a convergir. Por exemplo, há um pico nas figuras 5.8 e 5.9 após o quadro 150 que dura aproximadamente até o quadro 180.

Na figura 5.12, há uma visualização da odometria calculada para a cena 2. É possível observar a diferença entre o Fusion e o método proposto. São várias setas distantes da linha azul e uma faixa sem setas próximas, faixa esta relativa ás poses no intervalo dos quadros 150 à 200. 


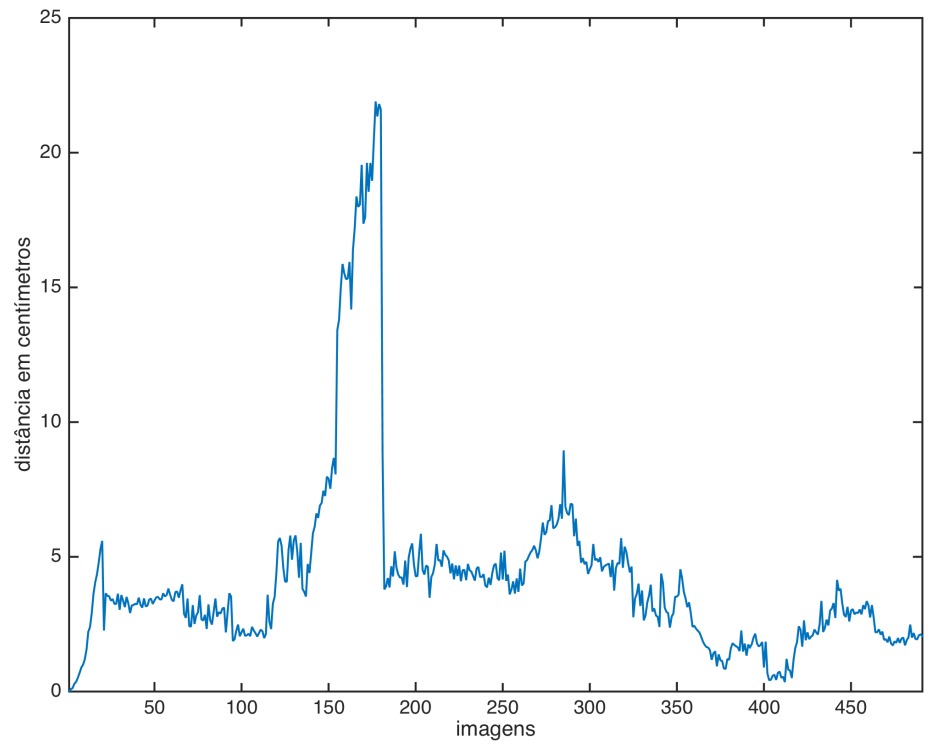

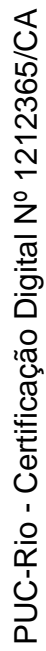

Figura 5.8: Distância em centímetros em relação ao Fusion (cena 2)

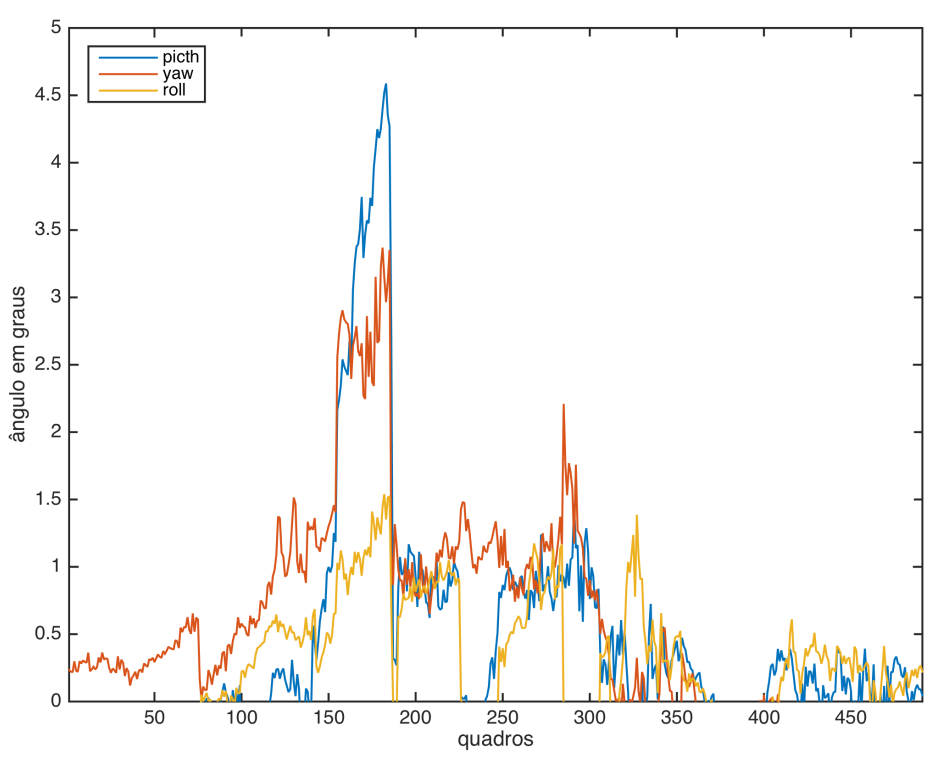

Figura 5.9: Ângulos de Euler sobrepostos da pose calculada em relação ao Kinect Fusion. Convenção: roll(X)-pitch(Y)-yaw(Z) (cena 2) 
Utilizando reconstrução 3D densa para odometria visual baseada em técnicas de structure from motion

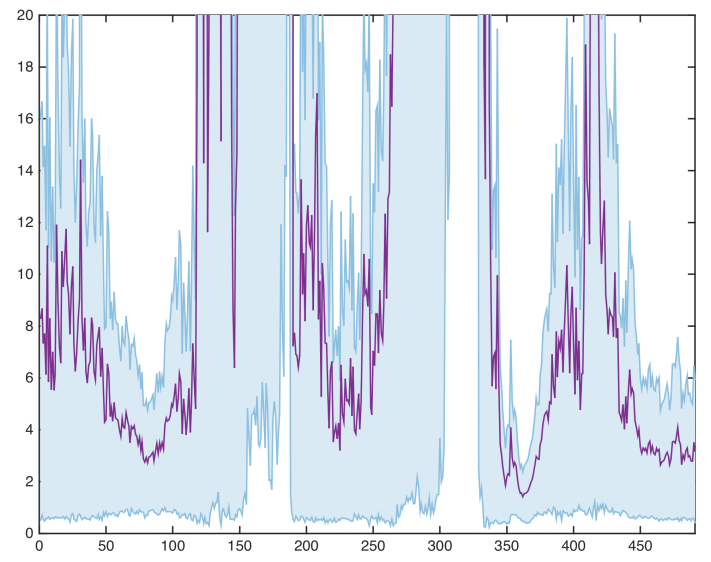

(a) detalhes

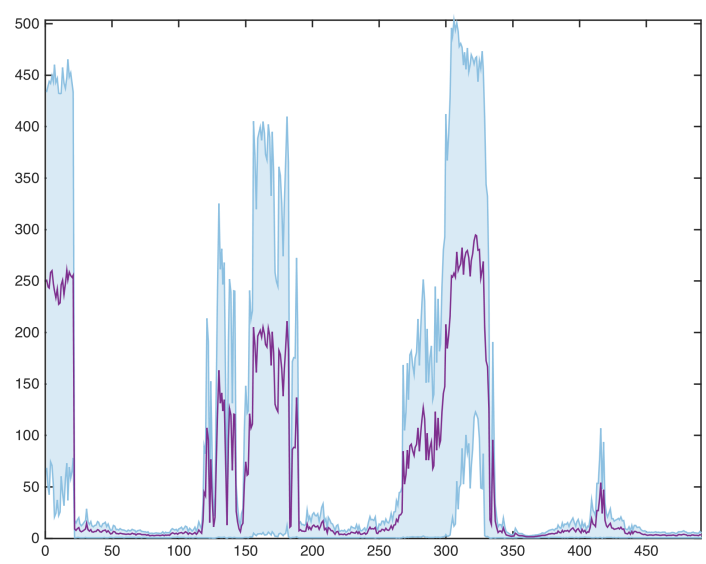

(b) visão geral

Figura 5.10: Eixo Y, mediana do erro de reprojeção em roxo. Área em ciano, valor da mediana limitada por MAD. Eixo X, imagens 
Utilizando reconstrução 3D densa para odometria visual baseada em técnicas de structure from motion

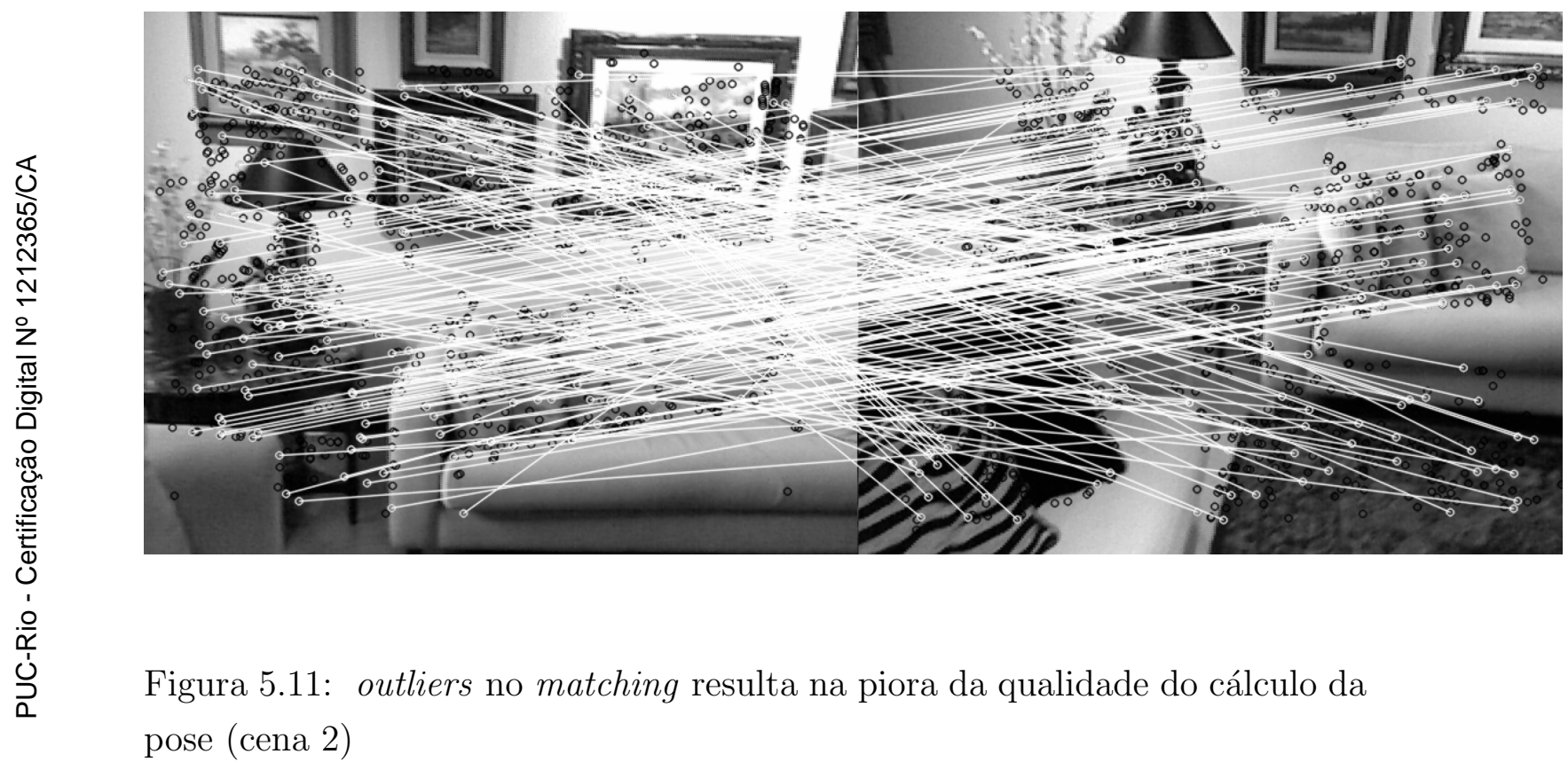


Utilizando reconstrução 3D densa para odometria visual baseada em técnicas de structure from motion

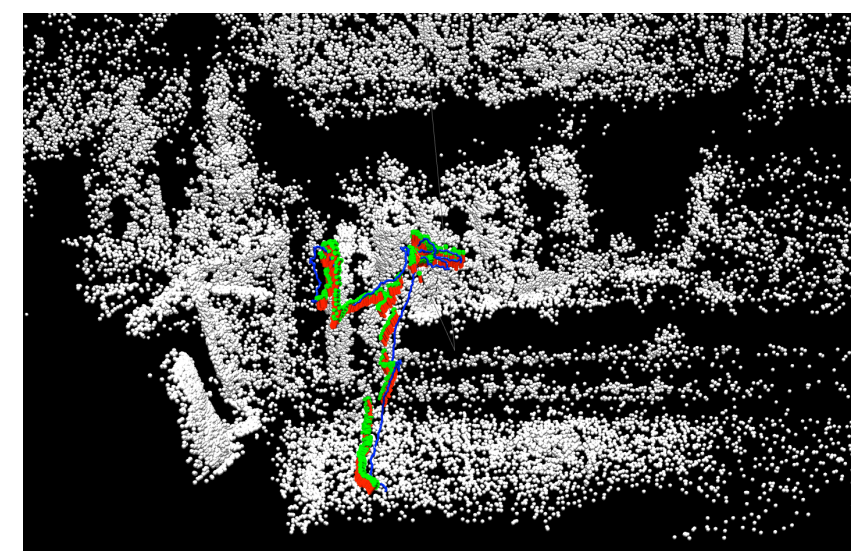

(a) visão geral

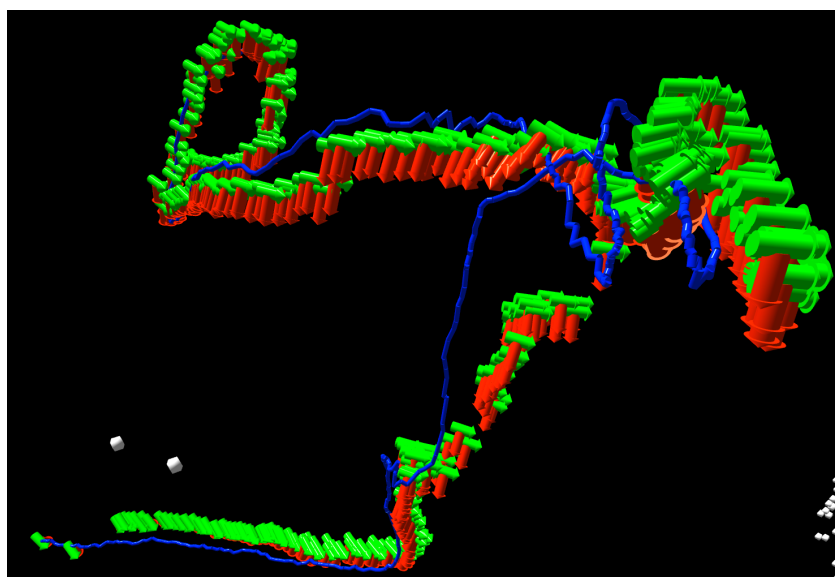

(b) vista lateral

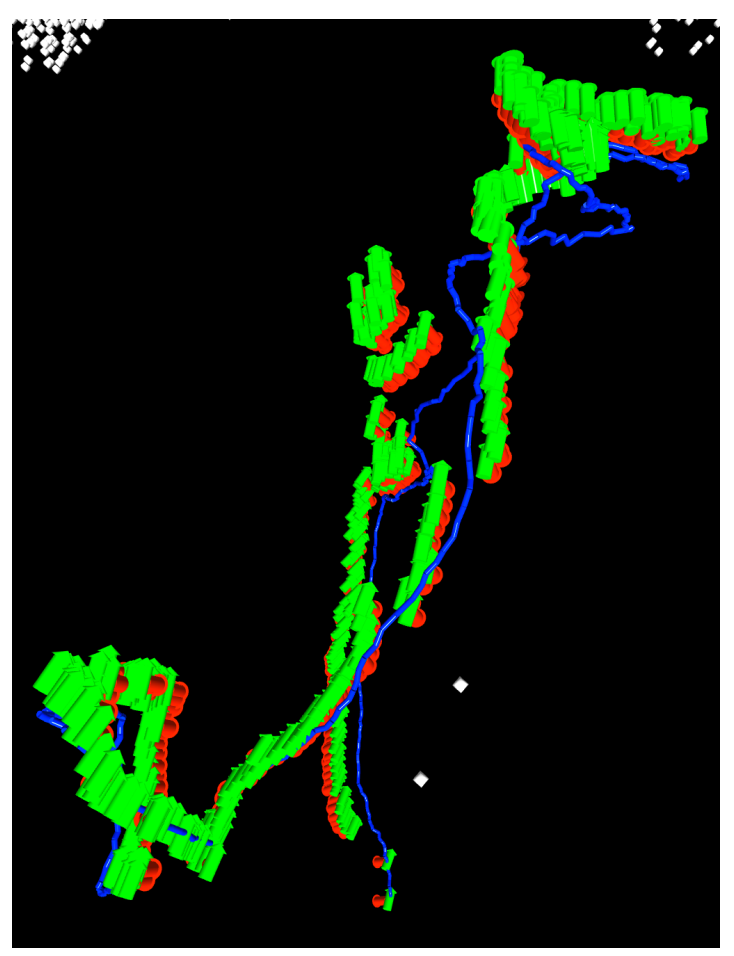

(c) vista de topo

Figura 5.12: Visualização 3D da odometria calculada (cena 2) 


\section{Conclusão e Trabalhos Futuros}

Este trabalho propôs um método para utilizar dados de uma reconstrução densa feita pelo Kinect Fusion, com um pipeline para cálculo da odometria utilizando features esparsos. Nos experimentos realizados o método conseguiu calcular em tempo real a pose, observando os requisitos para o funcionamento do mesmo, tendo no pior caso uma distância de $23 \mathrm{~cm}$ em relação a odometria do Fusion. Os requisitos restrigem o método para áreas internas com iluminação e a utilização de uma agente que não mova a câmera com grande velocidade (o ângulo máximo registrado entre pose e keyframe foi de 20 graus). Na primeira cena foram obtidos resultados mais próximos aos da odometria calculada pelo Kinect Fusion. Neste experimento a iluminação estava mais uniforme sem áreas com sombra como na cena 2. Embora observada a diferença na iluminação, não foi possível precisar sua influência no experimento. O método proposto não apresenta nenhum estado para recuperação caso não haja convergência no cálculo da pose ou haja um movimento grande entre duas poses.

A cena 2 possui o dobro da quantidade de keypoints por quadro. Entretando os resultados da odometria foram piores que na cena 1. O maior número de keypoints impactou a performance com a cena 2 tendo 22,2 FPS contra 29,8 FPS da cena 1. No estágio de matching encontra-se o gargalo do método proposto com o cálculo dos keypoints SURF. A quantidade dos keypoints impacta todos os componentes e um maior número não significou melhora na qualidade do cálculo da pose. O descarte de keypoints é feito apenas com um limiar no valor do determinante da Hessiana do detector SURF. Um método que leve em conta a distribuição espacial dos keypoints como em [37] pode escolher menos keypoints com mais qualidade.

O uso de um valor fixo para a região de outlier na função de perda não é o ideal e uma análise estatística da distribuição do erro de reprojeção se faz necessária, algo similar ao feito em [38]. Outra sugestão de trabalho futuro é a utilização de um modelo de velocidade como usado no PTAM; a posição dos keypoints poderia ser prevista e a busca de vizinhos mais próximos poderia ser feita apenas em uma área ao redor desta posição. Este estudo pode melhorar a performance e qualidade do matching.

Uma aplicação prática para o método apresentado seria utilizar a odometria calculada em aplicações de realidade aumentada, junto à malha 3D fornecida pelo Kinect Fusion. Esta malha pode ser usada para a oclusão 
Utilizando reconstrução 3D densa para odometria visual baseada em técnicas de structure from motion

de objetos virtuais e reais.

Outra utilização do método seria em aplicações multiusuário de realidade aumentada. Quando há mais de um Kinect observando uma mesma área, há uma interferência na leitura do mapa de profundidade. Uma forma de contornar esta limitação é que apenas um usuário use o Kinect Fusion. Os demais usariam a odometria visual deste trabalho, com uso de câmeras comuns. 


\section{Referências Bibliográficas}

[1] Rafael PD Vivacqua, Felipe N Martins, and Raquel F Vassallo. Visual lane tracking and prediction for autonomous vehicles. In Simpósio Brasileiro de Automação Inteligente (SBAI), 2013. 1

[2] Alexandre S Brandão, Felipe N Martins, and Higor B Soneguetti. A vision-based line following strategy for an autonomous uav. In International Conference on Informatics in Control, Automation and Robotics (ICINCO), 2015. 1

[3] Hans P Moravec. Obstacle avoidance and navigation in the real world by a seeing robot rover. Technical report, DTIC Document, 1980. 1

[4] Yi Ma. An invitation to 3-d vision: from images to geometric models, volume 26. Springer Science \& Business Media, 2004. 1, 3.3.1, 3.3.2

[5] Microsoft. photosynth is based on photo tourism, a research project by university of washington graduate student noah snavely. https://www.photosynth.net, 2015. 1

[6] Andrew J Davison, Ian D Reid, Nicholas D Molton, and Olivier Stasse. Monoslam: Real-time single camera slam. Pattern Analysis and Machine Intelligence, IEEE Transactions on, 29(6):1052-1067, 2007. 1, 2.1

[7] Georg Klein and David Murray. Parallel tracking and mapping for small ar workspaces. In Mixed and Augmented Reality, 200\%. ISMAR $200 \%$. 6th IEEE and ACM International Symposium on, pages 225-234. IEEE, 2007. 1

[8] Giorgio Grisetti, Rainer Kummerle, Cyrill Stachniss, and Wolfram Burgard. A tutorial on graph-based slam. Intelligent Transportation Systems Magazine, IEEE, 2(4):31-43, 2010. 1, 2.1

[9] Yasutaka Furukawa and Jean Ponce. Accurate, dense, and robust multi-view stereopsis. IEEE Trans. on Pattern Analysis and Machine Intelligence, 32(8):1362-1376, 2010. 1

[10] Richard A Newcombe, Shahram Izadi, Otmar Hilliges, David Molyneaux, David Kim, Andrew J Davison, Pushmeet Kohi, Jamie Shotton, Steve Hodges, and Andrew Fitzgibbon. Kinectfusion: Real-time 
dense surface mapping and tracking. In Mixed and augmented reality (ISMAR), 2011 10th IEEE international symposium on, pages 127-136. IEEE, 2011. 1, 3.7

[11] Davide Scaramuzza and Friedrich Fraundorfer. Visual odometry [tutorial]. Robotics \& Automation Magazine, IEEE, 18(4):80-92, 2011. 2

[12] David Nistér, Oleg Naroditsky, and James Bergen. Visual odometry. In Computer Vision and Pattern Recognition, 2004. CVPR 2004. Proceedings of the 2004 IEEE Computer Society Conference on, volume 1, pages I-652. IEEE, 2004. 2.1

[13] C. G. Harris and J. M. Pike. 3d positional integration from image sequences. Image Vision Comput., 6(2):87-90, May 1988. ISSN 0262-8856. doi: 10.1016/0262-8856(88)90003-0. URL http://dx.doi.org/10.1016/0262-8856(88)90003-0. 2.1

[14] Edward Rosten and Tom Drummond. Machine learning for high-speed corner detection. In Computer Vision-ECCV 2006, pages 430-443. Springer, 2006. 2.1

[15] Herbert Bay, Tinne Tuytelaars, and Luc Van Gool. Surf: Speeded up robust features. In Computer vision-ECCV 2006, pages 404-417. Springer, 2006. 2.1, 3.6

[16] Alexandre Alahi, Raphael Ortiz, and Pierre Vandergheynst. Freak: Fast retina keypoint. In Computer Vision and Pattern Recognition (CVPR), 2012 IEEE Conference on, pages 510-517. Ieee, 2012. 2.1, 3.5, 3.5.1

[17] Richard I Hartley and Peter Sturm. Triangulation. Computer vision and image understanding, 68(2):146-157, 1997. 2.1

[18] Bert M Haralick, Chung-Nan Lee, Karsten Ottenberg, and Michael Nölle. Review and analysis of solutions of the three point perspective pose estimation problem. International journal of computer vision, 13 (3):331-356, 1994. 2.1

[19] Martin A Fischler and Robert C Bolles. Random sample consensus: a paradigm for model fitting with applications to image analysis and automated cartography. Communications of the ACM, 24(6):381-395, 1981. 2.1

[20] Stephan Weiss, Markus W Achtelik, Simon Lynen, Margarita Chli, and Roland Siegwart. Real-time onboard visual-inertial state estimation and 
Utilizando reconstrução 3D densa para odometria visual baseada em técnicas de structure from motion

self-calibration of mavs in unknown environments. In Robotics and Automation (ICRA), 2012 IEEE International Conference on, pages 957-964. IEEE, 2012. 2.1

[21] Richard A Newcombe, Steven J Lovegrove, and Andrew J Davison. Dtam: Dense tracking and mapping in real-time. In Computer Vision (ICCV), 2011 IEEE International Conference on, pages 2320-2327. IEEE, 2011. 2.2

[22] Yang Chen and Gérard Medioni. Object modeling by registration of multiple range images. In Robotics and Automation, 1991. Proceedings., 1991 IEEE International Conference on, pages 2724-2729. IEEE, 1991. 2.2

[23] Szymon Rusinkiewicz and Marc Levoy. Efficient variants of the icp algorithm. In 3-D Digital Imaging and Modeling, 2001. Proceedings. Third International Conference on, pages 145-152. IEEE, 2001. 2.2

[24] Tommi Tykkala, Cédric Audras, and Andrew I Comport. Direct iterative closest point for real-time visual odometry. In Computer Vision Workshops (ICCV Workshops), 2011 IEEE International Conference on, pages 2050-2056. IEEE, 2011. 2.2

[25] G. Bradski. The OpenCV Library. Dr. Dobb's Journal of Software Tools, 2000. 3.2.2, 4.1.1

[26] Kaare Brandt Petersen, Michael Syskind Pedersen, et al. The matrix cookbook. Technical University of Denmark, 7:15, 2008. 3.3.1

[27] Peter J Huber et al. Robust estimation of a location parameter. The Annals of Mathematical Statistics, 35(1):73-101, 1964. 3.4 .3

[28] Matthew Brown and David G Lowe. Invariant features from interest point groups. In $B M V C$, number s 1, 2002. 3.6

[29] Buyue Zhang and Jan P Allebach. Adaptive bilateral filter for sharpness enhancement and noise removal. Image Processing, IEEE Transactions on, 17(5):664-678, 2008. 3.7.1

[30] Marius Muja and David G. Lowe. Scalable nearest neighbor algorithms for high dimensional data. Pattern Analysis and Machine Intelligence, IEEE Transactions on, 36, 2014. 4.2.1

[31] Jose luis Blanco. A tutorial on se(3) transformation parameterizations and on-manifold optimization, 2014. 4.2.2 
Utilizando reconstrução 3D densa para odometria visual baseada em técnicas de structure from motion

[32] Sameer Agarwal, Keir Mierle, and Others. Ceres solver.

http://ceres-solver.org, 2015. 4.2.2

[33] Wikipedia. Automatic differentiation, 2015.

http://en.wikipedia.org/wiki/Automatic_differentiation. 4.2.2

[34] K. Madsen, H. B. Nielsen, O. Tingleff, and Mathematical Modelling. Imm methods for non-linear least squares problems, 2004. 4.2.2

[35] John Sachs. Robust dual scaling with tukey's biweight. Applied psychological measurement, 18(4):301-309, 1994. 4.2.2

[36] Jose Luis Blanco et al. Mobile robot programming toolkit (mrpt). http://www.mrpt.org, 2015. 5.1

[37] Steffen Gauglitz, Luca Foschini, Matthew Turk, and Tobias Höllerer. Efficiently selecting spatially distributed keypoints for visual tracking. In Image Processing (ICIP), 2011 18th IEEE International Conference on, pages 1869-1872. IEEE, 2011. 6

[38] Christian Kerl, Jurgen Sturm, and Daniel Cremers. Robust odometry estimation for rgb-d cameras. In Robotics and Automation (ICRA), 2013 IEEE International Conference on, pages 3748-3754. IEEE, 2013. 6 